\title{
Frans De POTTER - JAN BROECKAERTPRIJS 2019: MARIE CHRISTINE LALEMAN
}

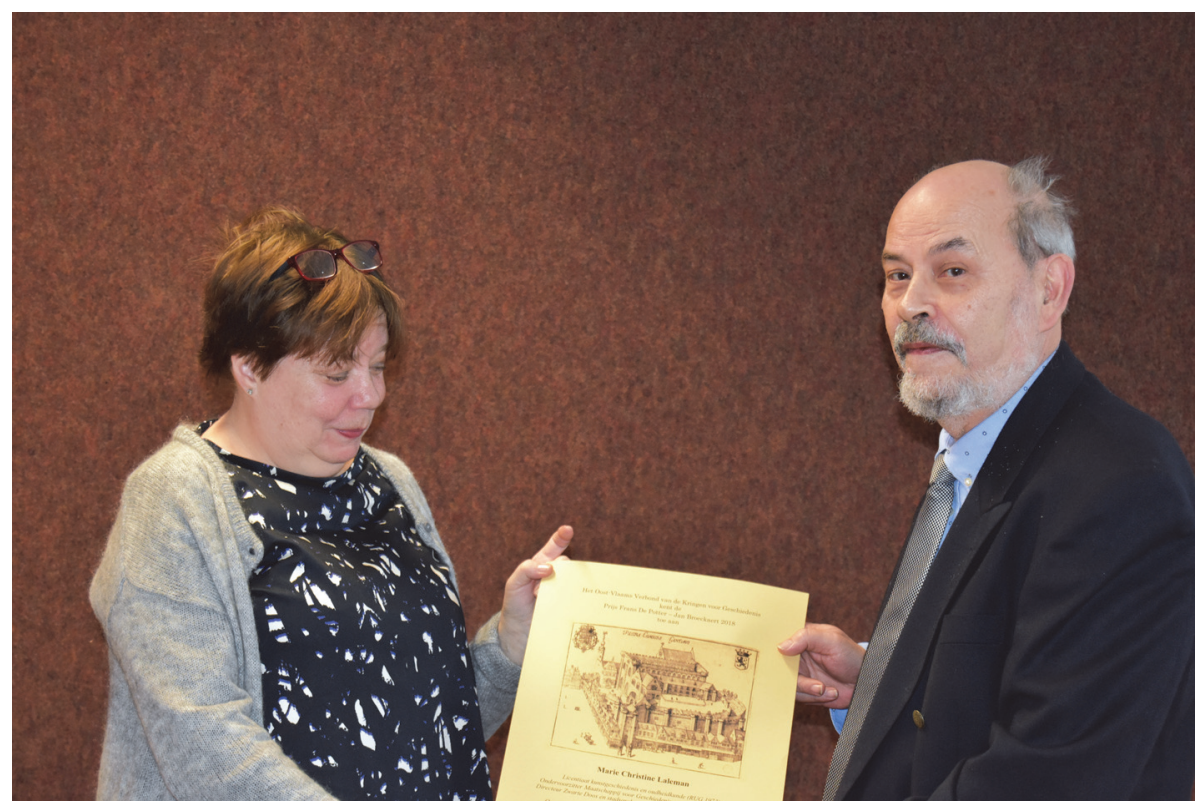

Op 26 januari 2019, tijdens de jaarlijkse vergadering van het Oost-Vlaams verbond der Kringen voor Geschiedenis, te Rons, ontving Marie Christine Laleman de Frans De Potter Jan Broeckaertprijs uit handen van Leo Pée, voorzitter

\section{Curriculum vitae}

\section{Marie Christine Laleman}

Geboren in Gent op 10 mei 1952

Na Grieks-Latijnse Humaniora, studies geschiedenis en oudheidkunde aan de Universiteit Gent

Behaalde in 1973 met de grootste onderscheiding het licentiediploma voor de verhandeling 'Archeologische studie over het gebouwencomplex van de abdij Vauclair’ (promotor Prof. Dr. F. De Smidt)

Specialiseerde in middeleeuwse archeologie, architectuur en bouwbedrijf 
Van 1973 tot 2017 verbonden aan de Stad Gent met opeenvolgende aanstellingen als wetenschappelijk medewerker, assistent, conservator, stadsarcheoloog, adviseur, directeur

Behoorde tot het eerste stadsarcheologische team van België en had van 1976 tot 2017 de leiding van de Gentse Stadsarcheologie

Samen met archeoloog Patrick Raveschot als laureaten bekroond door de Academie voor Wetenschappen, Letteren en Schone Kunsten van België voor het onderzoeksproject 'Inleiding tot de studie van de woonhuizen in Gent, periode 11001300: de kelders'

Samen met het Stadsarchief, van 2005 tot 2016 betrokken bij de uitbouw van De Zwarte Doos als historisch kenniscentrum van de Stad Gent, van 2011 tot 2016 als directeur verantwoordelijk voor zowel Stadsarcheologie als Stadsarchief Gent

Coördinator van talrijke inter- en multidisciplinaire onderzoeksprojecten en samenwerkingsverbanden, voornamelijk met betrekking tot het Gentse verleden

Publicaties, voordrachten, medewerking aan tentoonstellingen en educatieve projecten rond stadsarcheologie en stadsgeschiedenis van Gent

Gastcolleges over stadsarcheologie, stadsontwikkeling en bouwarcheologie aan diverse universiteiten in binnen- en buitenland

In 1977 stichtend lid van de Gentse Vereniging voor Stadsarcheologie v.z.w., nu GVSALM, en tot 2016 redacteur van het tijdschrift 'Stadsarcheologie', later 'Stadsarcheologie. Bodem en monument in Gent'

In 1978 stichtend lid van Archaeologia Mediaevalis, in omgevormd tot v.z.w./a.s.b.l. Archaeologia Mediaevalis

In 1981 stichtend lid van en tot 2001 bestuurslid van Vereniging voor Industriële Archeologie en Textiel, Gent

In 1982 stichtend lid en bestuurslid van Vereniging voor Interdisciplinair Archeologisch-Natuurwetenschappelijk Onderzoek

Vanaf 1991 bestuurslid van de Maatschappij voor Geschiedenis en Oudheidkunde van Gent

Van 1991 tot 2004 lid van de Koninklijke Commissie voor Monumenten en Landschappen, Afd. Oost-Vlaanderen 
Van 1995 tot 2004 lid van de Vlaamse Archeologische Raad

Van 1997 tot 2004 namens de Stad Gent bestuurslid van de gemeentelijke v.z.w. Museum voor Volkskunde, omgevormd tot v.z.w. Huis van Alijn

Van 2000 tot 2014 namens de Stad Gent bestuurslid van de gemeentelijke v.z.w. Gent Cultuurstad

Van 2004 tot 2014 lid van de Koninklijke Commissie voor Monumenten en Landschappen

In 2010 lid van de wetenschappelijke adviesraad van de Duinenabdij Koksijde

In 2012 aangesteld als lid van de Comité Permanent van 'Château Gaillard European Castle Studies'

In 2017 aangesteld als lid van de Gemeentelijke adviesraad Onroerend Erfgoed Koksijde

In 2019 bekroond met de Prijs Frans De Potter - Jan Broeckaert van het OostVlaams Verbond van de Kringen voor Geschiedenis

Jurylid van talrijke examen- en prijzencommissies 


\section{Bibliografie Marie Christine Laleman}

(tot 28.02.2019)

\section{Publicaties}

\section{5}

'Het broedergebouw van Vauclair (13de eeuw)', Gentse Bijdragen tot de Kunstgeschiedenis, Gent, 1973-1975, pp. 61-78.

'De architectuur tussen de twee wereldoorlogen', in Gent, duizend jaar kunst en cultuur, Gent, 3, 1975, pp. 147-151.

'De 18de eeuw', in Gent, duizend jaar kunst en cultuur, Gent, 3, 1975, pp. 86-101

'De empirestijl', in Gent, duizend jaar kunst en cultuur, Gent, 3, 1975, pp. 109-112.

'De hedendaagse architectuur', in Gent, duizend jaar kunst en cultuur, Gent, 3, 1975, pp. 151-155.

'De neogotiek', in Gent, duizend jaar kunst en cultuur, Gent, 3, 1975, pp. 120-176.

'De renaissance en barok: de kerkelijke architectuur', in Gent, duizend jaar kunst en cultuur, Gent, 3, 1975, pp. 74-85.

$\&$ B. Baillieul, 'De romaanse en de gotische stijl', in Gent, duizend jaar kunst en cultuur, Gent, 3, 1975, pp. 35-42.

\& F. Van Tyghem, 'De Brabantse gotiek', in Gent, duizend jaar kunst en cultuur, Gent, 3, 1975, pp. 57-61.

\& F. Van Tyghem, 'Het eclectisme', in Gent, duizend jaar kunst en cultuur, in: Gent, 3, 1975, pp. 126-132.

\& F. Van Tyghem, 'Het neoclassicisme', in Gent, duizend jaar kunst en cultuur, Gent, 3, 1975, pp. 113-120.

\& F. Van Tyghem, 'De Nieuwe Stijlbeweging', in Gent, duizend jaar kunst en cultuur, Gent, 3, 1975, pp. 140-142.

\& F. Van Tyghem, 'Renaissance en barok: de burgerlijke architectuur', in Gent, duizend jaar kunst en cultuur, Gent, 3, 1975, pp. 68-74.

\& F. Van Tyghem, 'De vroeg-gotiek en de hooggotiek', in Gent, duizend jaar kunst en cultuur, Gent, 3, 1975, pp. 57-61.

\section{6}

'Joos Rooman en Lieven de Key', Vlaanderen, Tielt, 153, 1976, pp. 222-223. 
'De ontwikkeling van het Gentse huisgeveltype in de tweede helft van de 16de eeuw', Vlaanderen, Tielt, 153, 1976, pp. 207-217.

'De oude dakpan in onze streken', in: Vondsten uit de Leie te Deinze, Deinze, 1976, pp. 176-182.

\section{8}

\& J. Vandenhoute, G. Van Doorne, Werken aan het Stadhuis, Gent, 1978.

\section{9}

'Een Karolingisch kapiteel', in Oude koeien uit de gracht..., Gent, 1979, p. 11.

'Karolingisch kapiteel', Stadsarcheologie, Gent, 3/1, 1979, pp. 47-53.

'Vestingmuur met waltoren', in Oude koeien uit de gracht..., Gent, 1979, p. 9.

'De afvalput uit vlak 26', in De Sint-Pietersabdij te Gent. Historisch en archeologisch onderzoek, Gent, 1977-1979, pp. 220-223.

'Constructieresten in de zone bij de kerk', in De Sint-Pietersabdij te Gent. Historisch en archeologisch onderzoek, Gent, 1977-1979, pp. 197-209.

'De constructies uit de kazernetijd', in De Sint-Pietersabdij te Gent. Historisch en archeologisch onderzoek, Gent, 1977-1979, pp. 255-268.

'De infirmerie van het 'rode plan', in De Sint-Pietersabdij te Gent. Historisch en archeologisch onderzoek, Gent, 1977-1979, pp. 159-168.

'Het kalkovencomplex', in De Sint-Pietersabdij te Gent. Historisch en archeologisch onderzoek, Gent, 1977-1979, pp. 120-140.

'Kleine natuurstenen en bakstenen constructieresten', in De Sint-Pietersabdij te Gent. Historisch en archeologisch onderzoek, Gent, 1977-1979, pp. 210-219.

'De laat-gotische infirmeriekapel', in De Sint-Pietersabdij te Gent. Historisch en archeologisch onderzoek, Gent, 1977-1979, pp. 179-192.

'Het oudste infirmeriegebouw', in De Sint-Pietersabdij te Gent. Historisch en archeologisch onderzoek, Gent, 1977-1979, pp. 141-158.

'Het pitantie-priorijgebouw', in De Sint-Pietersabdij te Gent. Historisch en archeologisch onderzoek, Gent, 1977-1979, pp. 224-254.

'De spiltrap en de bijhorende baksteenconstructie', in De Sint-Pietersabdij te Gent. Historisch en archeologisch onderzoek, Gent, 1977-1979, pp. 169-178.

'De westmuur, een tuinmuur', in De Sint-Pietersabdij te Gent. Historisch en archeologisch onderzoek, Gent, 1977-1979, pp. 193-196.

\& J. Van Cleven, 'Kasteel Maaltebrugge, neogotische huiskapel', in Stadsarcheologie, Gent, 3/2, 1979, pp. 11-23. 
\& J. Vandenhoute, 'Methodiek van de opgravingen', in De Sint-Pietersabdij te Gent. Historisch en archeologisch onderzoek, Gent, 1977-1979, pp. 89-97.

\& J. Vandenhoute, G. Van Doorne, Werken aan het Stadhuis, Gent, 1979/2.

\section{0}

Monastieke architectuur: een weerspiegeling van leven en denken in de geest van de 'Regula Benedicti', in Benedictus in de Nederlanden, Gent, 3, 1980, pp. 5-104.

'Vroeg-middeleeuwse bewoningssporen te Gent', in Vroeg-middeleeuwse bewoning en verdediging in de Scheldevallei, Gent, 1980, pp. 11-12.

\& G. Desmet, 'Een bezienswaardigheid in het Gemeentelijk Museum te Melle. Dobbel Slot. Ruiterstatuette', De Gonde, Melle, 13, 1980, pp. 245-254.

\& G. Desmet, 'Dobbel Slot, ruiterstatuette', Stadsarcheologie, Gent, 4/1, 1980, pp. 27-39.

\& J. Vandenhoute, 'Journée Viking à Gand', Revue du Nord, Lille, 247, 1980, pp. 930-932.

\& J. Vandenhoute, G. Van Doorne, Werken aan het Stadhuis, Gent, 1980/3.

\section{1}

'Desmoulins Antoinette', Nationaal Biografisch Woordenboek, Brussel, 9, 1981, pp. 189191.

'Rooman Franciscus', Nationaal Biografisch Woordenboek, Brussel, 9, 1981, pp. 651-653.

'Stadsarcheologie... Een schakel in de stadsvernieuwing', Stadsarcheologie, Gent, 5/1, 1981, pp. 2-10.

'Van de vroege middeleeuwen tot de 19de eeuw', in Zoeken naar Oostakkers verleden, Gent, 1981, pp. 13-25.

\& P. Raveschot, 'Drongen, een middeleeuwse mote', in Stadsarcheologie, Gent, 5/2, 1981, pp. 2-26.

\& J. Vandenhoute, 'Bijdrage Stadsarcheologie', in Een eeuw zorg om monumentenzorg, Gent, 1981, pp. 210-214.

\section{2}

'Het eerste neogotische gebouw in Gent: een theehuisje aan de Leie', Kultureel Jaarboek van de Provincie Oost-Vlaanderen, Gent, 18, 1982, pp. 197-209.

'Het stadsarcheologisch onderzoek in Gent', VOBOV-Info, Belsele, 8-9, 1982-1983, pp. 21 24.

\& J. Vandenhoute, 'Stadsarcheologie. Het onderzoek van een levende, historische stad', Ons Heem, Genk, 36/1, 1982, pp. 1-6. 


\section{3}

'Het bouwbedrijf in de middeleeuwen, een familiale aangelegenheid?', in Genealogie en menselijke bedrijvigheid, Gent, 1983, pp. 7-8.

'Maertens de Noordhout Joseph', Nationaal Biografisch Woordenboek, Brussel, 10, 1983, pp. 417-420.

'Prof. Dr. Firmin De Smidt (1904-1983) en het archeologisch onderzoek in Gent', Stadsarcheologie, Gent, 7/2, 1983, pp. 29-35.

'Stadsarcheologie in Gent', in Aspecten van de archeologie in Vlaanderen, Koksijde, 1983, pp. 69-74.

\& J. Baldewijns, 'De stadsomwalling aan de Brugse Poort', Stadsarcheologie, Gent, 7/1, 1983, pp. 6-27.

\& P. Raveschot, 'Het stadsarcheologisch onderzoek in Gent', VOBOV-info, Belsele, 12, 1983, pp. 20-22.

\& P. Raveschot, R. Van de Walle, Archeologisch onderzoek aan de Poel, Stadsarcheologie, Gent, 7/3, 1983, pp. 2-12

\& P. Raveschot, R. Van de Walle, 'Einfluss und Import von deutschen Gebieten in Gent, ein Beitrag der stadtarchäologischen Untersuchung', in Ein Jahrbundert Denkmalpflege in Flandern, Köln, 1983, pp. 29-31.

\section{4}

'Gand et son enceinte urbaine du XIIe siècle. Apports de l'archéologie urbaine', in Actes du XLVIIe Congrès de la Fédération des Cercles d'Archéologie et d'Histoire de Belgique, Nivelles, 1, 1984, pp. 126-127.

'Gand et ses enceintes urbaines médiévales', in Actes du XLVIIe Congrès de la Fédération des Cercles d'Archéologie et d'Histoire de Belgique, Nivelles, 1984, pp. 201-211.

'Gotiek, renaissance of barok? Een spiegel van de Gentse architectuur in de 17de eeuw', in Gent \& architectuur. Trots, schande en herwaardering in een overzicht, Brugge, 1984, pp. 56-75.

'In stadsarcheologisch perspectief, in Het Toreken te Gent, Gent, 1984, pp. 12-14.

Transparant, een dokument over glasramen te Gent, Gent, 1984.

'Van tentenkampen tot 'Stenen zo hoog als torens'. De ontwikkeling van de Gentse architectuur in de preromaanse en romaanse tijd', in Gent \& architectuur. Trots, schande en herwaardering in een overzicht, Brugge, 1984, pp. 6-23.

\& J. Baldewijns, 'De architectuur van de Gentse begijnhoven', in Werken en Kerken 750 jaar begijnhofleven in Gent, Gent, 1984, pp. 53-92 \& pp. 157-186.

\& J. Baldewijns, Gids voor de Gentse begijnhoven, Gent, 1984. 
\& G. Deseyn, G. Van Doorne, 'De eerste gedaante van het gildehuis', in Het Toreken te Gent, Gent, 1984, pp. 18-28.

$\&$ B. Joos, "Op en om de Gentse restauratiewerven. De infirmerie en de brouwerij van het Caermersklooster in het Patershol, Toerisme in Oost-Vlaanderen, Gent, 33/2, 1984, pp. 49-59.

\& P. Raveschot, 'Wellingstraat 103, onderzoek van een laat-middeleeuwse woning', Stadsarcheologie, Gent, 8/3, 1984, pp. 18-38.

\& P. Raveschot, R. Van de Walle, 'Het bodemarchief onder het Toreken', in Het Toreken te Gent, Gent, 1984, pp. 15-17.

\section{5}

'Bouwmaterialen', in De Sint-Pietersabdij te Gent. Het rijke leven van zieke monniken. Twee afvalputten uit de infirmerie, 1600-1780, Gent, 1985, pp. 69-77.

\& D. Lievois, R. Raveschot, 'De stadsversterking bij de Zandpoort. Archeologisch en bouwhistorisch onderzoek', Stadsarcheologie. Bodem en Monument in Gent, Gent, 9/2, 1985, pp. 16-41.

\& P Raveschot, 'De twee afvalputten uit de infirmerie', in De Sint-Pietersabdij te Gent. Het rijke leven van zieke monniken. Twee afvalputten uit de infirmerie, 1600-1780, Gent, 1985, pp. 9-16.

\& P. Raveschot, P. Swimberghe, 'Tussen kranen en graafmachines ligt Gents verleden. Archeologisch onderzoek op bouwwerf in het stadscentrum', Toerisme in Oost-Vlaanderen, Gent, 34/4, 1985, pp. 91-94.

\& P. Raveschot, R. Van de Walle, 'Varia', in De Sint-Pietersabdij te Gent. Het rijkeleven van zieke monniken, twee afvalputten uit de infirmerie, 1600-1780, Gent, 1985, pp. 81-82.

$\&$ P. Raveschot, R. Van de Walle, 'Waarom deze publikatie?', in De Sint-Pietersabdij te Gent, het rijke leven van zieke monniken, twee afvalputten uit de infirmerie, 1600-1780, Gent, 1985, pp. 7-8.

\section{6}

'Gentse tegels uit de 14de eeuw', Stadsarcheologie. Bodem en Monument in Gent, Gent, $10 / 1,1986$, pp. $2-15$.

'Een middeleeuwse stadswijk in de schaduw van het Gravensteen', in Patershol Gent Binnenste Buiten, Gent, 1986, pp. 6-7.

'Stadsarcheologie in Gent', in Wat 'n leven binnen die muren! Gent 1100-1350, Gent, 1986, pp. 9-14.

'Stadsarcheologie morgen', in Wat 'n leven binnen die muren! Gent, 1986, pp. 109-114. 
\& D. Lievois, P. Raveschot, 'De top van de Zandberg. Archeologisch en bouwhistorisch onderzoek', Stadsarcheologie. Bodem en Monument in Gent, Gent, 10/2, 1986, pp. 2-61.

\& P. Raveschot, 'Binnen de omwalling: de Kuip', in Wat 'n leven binnen die muren! Gent 1100-1350, Gent, 1986, pp. 49-62.

\& P. Raveschot, 'Buiten de poorten', in Wat ' $n$ leven binnen die muren! Gent 1100-1350, Gent, 1986, pp. 67-74.

$\&$ P. Raveschot, 'Eredienst en dodenbestel', in Wat ' $n$ leven binnen die muren! Gent 1100 1350, Gent, 1986, pp. 107-108.

$\&$ P. Raveschot, 'Een stadsarcheologische inventaris voor Gent', in Wat ' $n$ leven binnen die muren! Gent 1100-1350, Gent, 1986, pp. 15-20.

\& P. Raveschot, P. Swimberghe, 'Stadswoningen', in Wat ' $n$ leven binnen die muren! Gent 1100-1350, Gent, 1986, pp. 77-95.

\& T Waegeman, P. Devos, W. Pottier, M. Goossens, A. Linters, P. De Gryse, L. Kindt, 'Over ruïnes en monumenten', Openbaar Kunstbezit in Vlaanderen, Gent, 24/4, 1986, pp. 122-127.

\section{7}

'Archeologie en monumentenzorg', De Leiegouw, Kortrijk, 29/1-2, 1987, pp. 159-166.

'Bruggenbouw, een overzicht', in 7 Bruggen: historiek \& restauratie van zeven Gentse Leiebruggen, Gent, 1987, pp. 9-30.

'Kom over de brug... De Gentse Leiebruggen', Toerisme in Oost-Vlaanderen, Gent, 36/1, 1987, pp. 12-16.

$\&$ D. Lievois, 'De Gentse Sint-Niklaaskerk. Archeologisch onderzoek in het koor', Stadsarcheologie. Bodem en Monument in Gent, Gent, 11/2, 1987, pp. 2-42.

\& D. Lievois, 'De Grasbrug', in 7 Bruggen: historiek \& restauratie van zeven Gentse Leiebruggen, Gent, 1987, pp. 61-68.

\& D. Lievois, 'De Krommewalbrug', in 7 Bruggen: historiek \& restauratie van zeven Gentse Leiebruggen, Gent, 1987, pp. 85-88.

\& D. Lievois, 'De Predikherenbrug', in 7 Bruggen: historiek \& restauratie van zeven Gentse Leiebruggen, Gent, 1987, pp. 47-52.

\& D. Lievois, 'De Recollettenbrug', in 7 Bruggen: historiek \& restauratie van zeven Gentse Leiebruggen, Gent, 1987, pp. 37-46.

\& D. Lievois, 'De Sint-Michielsbrug', in 7 Bruggen: historiek \& restauratie van zeven Gentse Leiebruggen, Gent, 1987, pp. 53-60.

\& D. Lievois, 'De Vleeshuisbrug', in 7 Bruggen: historiek \& restauratie van zeven Gentse Leiebruggen, Gent, 1987, pp. 69-78. 
\& D. Lievois, 'De Zuivelbrug', in 7 Bruggen: historiek \& restauratie van zeven Gentse Leiebruggen, Gent, 1987, pp. 79-84.

\& P. Raveschot, 'Middeleeuwse bewoning in de Gentse Hoogpoort', De Leiegouw, Kortrijk, 29/1-2, 1987, pp. 167-172.

\section{8}

'Een kijk op stadsarcheologie. Enkele aspecten van actueel stadsonderzoek', De Franse Nederlanden, Rekkem, 13, 1988, pp. 153-168.

'Een koe uit de Kalversteeg', Patersholnieuws, Gent, 3/1, 1988, pp. 13-15.

$\&$ D. Lievois, P. Raveschot, 'De geschiedenis achter de façade. Archeologisch en bouwhistorisch onderzoek aan de Kammerstraat', Stadsarcheologie. Bodem en Monument in Gent, Gent, 12/4, 1988, pp. 2-38.

$\&$ P. Raveschot, 'Gent. Onderzoek van een middeleeuwse stad', in Speuren, spitten, sparen. Oost-Vlaanderen archeologisch doorgelicht, Gent, 1988, pp. 87-91.

\& P. Raveschot, Steen voor Steen. Het onderzoek naar het middeleeuwse buis in Gent en de bijdrage van Amand Heins, Gent, 1988.

\section{9}

'Archeologie in het Patershol: ter inleiding', Stadsarcheologie. Bodem en Monument in Gent, Gent, 13/3, 1989, pp. 2-10.

'Archeologisch textiel uit de Gentse Sint-Niklaaskerk', Stadsarcheologie. Bodem en Monument in Gent, Gent, 13/4, 1989, pp. 5-7

'Steenhouwer Nicolas Paternotte', Stadsarcheologie. Bodem en Monument in Gent, Gent, 13/1, 1989, pp. 37-53.

\& G. Everaert, D. Lievois, P. Raveschot, 'De geschiedenis achter de façade. Bouwhistorisch onderzoek van het huis Kammerstraat 10', Stadsarcheologie. Bodem en Monument in Gent, Gent, 13/1, 1989, pp. 23-36.

\& D. Lievois, P. Raveschot, 'De geschiedenis achter de façade. Bouwhistorisch onderzoek van het huis Kammerstraat 2', Stadsarcheologie. Bodem en Monument in Gent, Gent, 13/1, 1989, pp. 2-8.

\& D. Lievois, P. Raveschot, 'De geschiedenis achter de façade. Bouwhistorisch onderzoek van het huis Kammerstraat 4', Stadsarcheologie. Bodem en Monument in Gent, Gent, 13/1, 1989, pp. 9-13.

\& D. Lievois, P. Raveschot, 'De geschiedenis achter de façade. Bouwhistorisch onderzoek van het huis Kammerstraat 6', Stadsarcheologie. Bodem en Monument in Gent, Gent, 13/1, 1989, pp. 14-17. 
\& D. Lievois, P. Raveschot, 'De geschiedenis achter de façade. Bouwhistorisch onderzoek van het huis Kammerstraat 8', Stadsarcheologie. Bodem en Monument in Gent, Gent, 13/1, 1989, pp. 18-22.,

\& D. Lievois, P. Raveschot, 'De geschiedenis achter de façade. Bouwhistorisch onderzoek van het huis Kammerstraat 12', Stadsarcheologie. Bodem en Monument in Gent, Gent, 13/2, 1989, pp. 3-10.

$\&$ D. Lievois, P. Raveschot, 'De geschiedenis achter de façade. Archeologisch en bouwhistorisch onderzoek van de panden Kammerstraat 14 en 16', Stadsarcheologie. Bodem en Monument in Gent, Gent, 13/2, 1989, pp. 11-21.

\& D. Lievois, P. Raveschot, 'De geschiedenis achter de façade. Bouwhistorisch onderzoek van het huis Kammerstraat 18', Stadsarcheologie. Bodem en Monument in Gent, Gent, 13/2, 1989, pp. 31-37.

\& D. Lievois, P. Raveschot, 'De geschiedenis achter de façade. Bouwhistorisch onderzoek van het huis Kammerstraat 20', Stadsarcheologie. Bodem en Monument in Gent, Gent, 13/2, 1989, pp. 38-42.

\& D. Lievois, P. Raveschot, De geschiedenis achter de façade. Bouwhistorisch onderzoek van het huis Kammerstraat 22', Stadsarcheologie. Bodem en Monument in Gent, Gent, 13/2, 1989, pp. 43-57.

\& D. Tavernier, 'De buitentuin van de Sint-Pietersabdij', (Open Monumentendag Gent, 10 september 1989), Gent, 1989.

\& H. Thoen, 'Le berceau de la ville, préhistoire - sixième siècle après J.C.', in J. Decavele (dir.), Gand, apologie d'une ville rebelle, Anvers, 1989, pp. 22-35.

$\&$ H. Thoen, 'The birth of the City', in J. Decavele (dir.), Ghent, in defence of a rebellious city, Antwerp, 1989, pp. 22-36.

\& H Thoen, 'Bij de wieg van de stad, prehistorie - zesde eeuw na Chr.', in J. Decavele (dir.), Gent, apologie van een rebelse stad, Antwerpen, 1989, pp. 22-35.

$\& \mathrm{H}$. Thoen, 'Gand au confluent des principales rivières de Flandre', in J. Decavele (dir.), Gand, apologie d'une ville rebelle, Anvers, 1989, pp. 16-21.

$\& \mathrm{H}$. Thoen, 'Gent, aan de samenvloeiing van Vlaanderens belangrijkste rivieren', in J. Decavele (dir.), Gent, apologie van een rebelse stad, Antwerpen, 1989, pp. 16-21.

$\&$ H. Thoen, 'Ghent, at the confluence of Flanders' two most important rivers', in J. Decavele (dir.), Ghent, in defence of a rebellious city, Antwerp, 1989, pp. 16-21.

\section{0}

'Een bericht over archeologisch onderzoek naar de middeleeuwen en moderne tijden in de provincie Oost-Vlaanderen', Vobov-info, Belsele, 38-40, 1990, pp. 71-81. 
'De Gouvernementstraat in Gent. Denkwerk bij een noodonderzoek', Stadsarcheologie. Bodem en Monument in Gent, Gent, 14/4, 1990, pp. 3-11.

'Monumenten en archeologisch erfgoed', in Inleiding tot de monumentenzorg, (Instituut voor Conservatie en Restauratie), Gent, 1990.

'Monumenten en archeologisch erfgoed', in Vlaamse archeologie. Opgravingen in binnen-en buitenland, Oudenburg, 1990, pp. 51-55.

'De oudste stenen burgerwoningen in Gent', in Handelingen van het eerste Congres van de Federatie van Nederlandstalige Verenigingen voor Oudheidkunde en Geschiedenis van België te Hasselt, 19-22 augustus 1982, Mechelen, 2, 1990, pp. 129-142.

'Vooronderzoeken bij restauratie en renovatie', in Inleiding tot de monumentenzorg, (Instituut voor Conservatie en Restauratie), Gent, 1990.

\& M Boone, D; Lievois, "Van Simon sRijkensteen tot Hof van Ryhove. Van erfachtige lieden tot dienaren van de centrale Bourgondische staat, Handelingen der Maatschappij voor Geschiedenis en Oudheidkunde, Gent, 44, 1990, pp. 47-86.

\& G. De Smet, Gent. Onbekende rijkdom. Richesse inconnue, Gent, 1990.

\& H. De Witte, T. Oost, 'Stadsarcheologie in Vlaanderen', in Vlaamse Archeologie. Opgravingen in binnen-en buitenland, Oudenburg, 1990, pp. 45-50.

\& P. Raveschot, 'Nieuwe bevindingen over de donjon van het Gravensteen in Gent', Stadsarcheologie, Gent, 14/4, 1990, pp. 86-94.

$\&$ A. Verhulst, 'Archeologische en historische visies op het ontstaan en de vroege ontwikkeling van Gent in confrontatie', in Ontstaan en vroegste geschiedenis van de middeleeuwse steden in de zuidelijke Nederlanden, (Historische Uitgaven van het Gemeentekrediet, 83), Brussel, 1990, pp. 299-315.

\section{1}

'Maisons médiévales en pierre à Gand. Apport de l'archéologie urbaine', in Nouvelles approches concernant la culture de l'habitat, Turnhout, 1991, pp. 89-98.

'Een terugblik in de tijd', in De Sint-Baafskathedraal in Gent, Monument en heiligdom, (Openbaar kunstbezit in Vlaanderen, 4), Tielt, 1991, pp. 122-134.

\& A. Ervynck, A. Lentacker, P. Raveschot, Dobbelslot-ridderslot, Gent, 1991.

$\&$ D. Lievois, 'Een 17de-eeuws bastion buiten de Kortrijkse Poort', Stadsarcheologie. Bodem en monument in Gent, Gent, 15/1, 1991, pp. 5-33.

$\&$ D. Lievois, 'Het Tweede Pandhof van het Karmelietenklooster', Stadsarcheologie. Bodem en monument in Gent, Gent, 15/4, 1991, pp. 16-30.

\& P. Raveschot, 'Enkele kritische bedenkingen over Gentse ruiterstatuettes', Stadsarcheologie. Bodem en monument in Gent, Gent, 15/1, 1991, pp. 34-42. 
\& P. Raveschot, 'Gents duister verleden. Een bescheiden bijdrage van de archeologie voor de kennis over de ontwikkeling tussen 400 en 1200', in Archaeologia Mediaevalis. Colloquium bruxellensis, Brussel, 1, 1991, pp. 23-28.

\& P. Raveschot, Inleiding tot de studie van de woonhuizen in Gent. Periode 1100-1300. De kelders, (Verhandelingen Koninklijke Academie voor Wetenschappen, Letteren en Schone Kunsten van België), Brussel, 1991.

\section{2}

'De Gentse Stenen: getuigen van handel in laken, graan en bouwstenen (11de-14de eeuw)', Rotterdam Papers, Rotterdam, 7, 1992, pp. 61-73.

De Sint-Pietersabdij te Gent. Dertien eeuwen Geschiedenis en Cultuur, Gent, 1992.

'Van materieel spoor tot boek. Nieuwe wegen voor het huizenonderzoek in Gent', Stadsarcheologie. Bodem en monument in Gent, Gent, 16/2, 1992, pp. 5-8.

\& L. Bauters, D. Lievois, P. Raveschot, 'Het klooster van de geschoeide karmelieten. Nieuwe archeologische en bouwhistorische gegevens', Stadsarcheologie. Bodem en monument in Gent, Gent, 16/4, 1992, pp. 7-50.

\& R. De Herdt, J. Vannieuwenhuyse, 'Bibliografie van de geschiedenis van Gent 19911992', Handelingen der Maatschappij voor Geschiedenis en Oudheidkunde, Gent, XLVI, 1992, pp. 257-294.

\& A. Ervynck, P. Raveschot, 'Knopen, kralen of ringetjes? Botbewerking in het klooster van de geschoeide karmelieten', Stadsarcheologie. Bodem en monument in Gent, Gent, 16/4, 1992, pp. 51-55.

\& G. Everaert, D. Lievois, 'Het huis met de houten achtergevel. Een nieuwe synthese', Stadsarcheologie. Bodem en monument in Gent, Gent, 16/3, 1992, pp. 21-36.

\& P. Raveschot, 'L'hôpital de la Bijloke à Gent: premier bilan de la recherche archéologique', in Actes LIe Congrès de la Fédération des Cercles d'Archéologie et d'Histoire de la Belgique, Liège, 1, 1992, pp. 98-100.

\& P. Raveschot,' Restauratie van gebouwen, behoud en vernieling van erfgoed', Bulletin Koninklijke Nederlandse Oudheidkundige Bond, Zutphen, 2, 1992, pp. 64-69.

\& P. Raveschot, 'Vanuit het heden een kijk op het Gentse verleden. Een nieuw gezicht voor Sint-Macharius', Toerisme in Oost-Vlaanderen, Gent, 41/2, 1992, pp. 51-54.

\& P. Raveschot, 'De Ziekenzaal van de Bijloke. Renovatie en onderzoek in Gent', Toerisme in Oost-Vlaanderen, Gent, 41/3, 1992, pp. 76-80.

\section{3}

De middeleeuwse vensters, in Vensters, zeven eeuwen techniek en esthetiek, Gent, 1993, pp. 20-34. 
'L'organisation de l'archéologie en Belgique', in V Negri (dir.), L'organisation territoriale de l'archéologie en Europe, (Actes des rencontres européennes, Montpellier 22-23-24 mai 1991), Nancy, 1993, pp. 27-35.

(red.), 'Patrick Raveschot (1950-1993) en het archeologisch onderzoek in Gent', Stadsarcheologie. Bodem en Monument in Gent, Gent, 17/1, 1993, pp. 5-21.

\& L Bauters, 'De dakconstructie van de Karmelietenkerk. Eerste dendrochronologische analyse', Stadsarcheologie. Bodem en Monument in Gent, Gent, 17/2, 1993, pp. 35-40.

\& D. Cardon, J. Lagae, J. Lefebure, Dag van de architectuur. Toekomst verzekerd! Reconversie, een nieuwe functie voor het bestaande, Gent, 1993.

\& R. De Herdt, J. Vannieuwenhuyse, 'Bibliografie van de geschiedenis van Gent 1992 1993', Handelingen der Maatschappij voor Geschiedenis en Oudheidkunde, Gent, XLVII, 1993, pp. 127-187.

\& G. Everaert, D. Lievois, 'De tweede ziekenzaal van de Bijloke', Stadsarcheologie. Bodem en Monument in Gent, Gent, 17/4, 1993, pp. 5-23.

$\&$ D. Lievois, 'De 16de-eeuwse glasmakersfamilie Lonis', Stadsarcheologie. Bodem en monument in Gent, Gent, 17/3, 1993, pp. 5-45.

\& D. Lievois, G; Stoops,' Het gedenkteken voor Jan Frans Willems op het Sint-Baafsplein', Stadsarcheologie. Bodem en monument in Gent, Gent, 17/2, 1993, pp. 5-27.

\section{4}

'L'archéologie de la ville en Belgique: quelques réflexions', in Actes du LIe Congrès de la Fédération des Cercles d'Archéologie et d'Histoire de Belgique, Liège, 2, 1994, pp. 122-128.

'Gruuthuus en de Grutere', in R.E. Kistemaker \& V.T. van Vilsteren, Bier! Geschiedenis van een volksdrank, Amsterdam, 1994, p. 23.

'Van materieel spoor tot huizengeschiedenis in Gent', in Huizenonderzoek in Gent, Gent, 1994, pp. 7-20.

'La ville au XIIIe siècle: Apports de l'archéologie urbaine', in M. Margue (red.), Ermesinde et l'affranchissement de la ville de Luxembourg. Etudes sur la femme, le pouvoir et la ville au XIIIe siècle, Luxembourg, 1994, pp. 255-272.

\& L. Bauters, 'De kerk van de Geschoeide Karmelieten. Beschouwingen bij een dakonderzoek', Stadsarcheologie. Bodem en Monument in Gent, Gent, 18/2, 1994, pp. 35-40.

\& L. Bauters, 'Het klooster van de Geschoeide Karmelieten in Gent (O.Vl.)', Archaeologia Mediaevalis, Brussel, 17, 1994, p. 31.

\& L. Bauters, A. Lens, D. Lievois, G. Stoops, 'De grafsteen van Antoon Van Hille in de kerk van de Geschoeide Karmelieten te Gent', Stadsarcheologie. Bodem en Monument in Gent, Gent, 18/2, 1994, pp. 5-28. 
\& R. De Herdt, J. Vannieuwenhuyse, 'Bibliografie van de geschiedenis van Gent 19931994', Handelingen der Maatschappij voor Geschiedenis en Oudheidkunde, Gent, XLVIII, 1994, pp. 233-278.

\& J. De Meulemeester, A. Matthys (red.), Archaeologia Mediaevalis. Middeleeuwse archeologie in de zuidelijke Nederlanden en aangrenzende gebieden, Brussel, 17, 1994.

\& G. Everaert, 'Gebruik van het bouwhistorisch onderzoek - een evaluatie', in Huizenonderzoek in Gent, Gent, 1994, pp. 123-125.

\& L. Lichtenberg, 'Verrassingen en onzekerheden bij unieke restauratie. Refter van de Gentse Sint-Pietersabdij toont geleidelijk meer haar grootsheid', Scarabee, 's Gravenhage, 10, 1994, pp. 5-9.

\& P. Raeschot (+), 'L'hôpital de la Bijloke à Gent: premier bilan de la recherche archéologique', in Actes du LIe Congrès de la Fédération des Cercles d'Archéologie et d'Histoire de Belgique, Liège, 2, 1994, pp. 129-135.

\section{5}

'Bijzondere vorsten. Hardstenen nokafdekking uit de 17de eeuw', Stadsarcheologie. Bodem en Monument in Gent, Gent, 19/3, 1995, pp.21-33.

'Poorten en deuren. Middeleeuwen', in Deuren \& poorten. Zeven eeuwen techniek en esthetiek, Gent, 1995, pp. 16-33.

\& L. Charles, R. De Herdt, 'Bibliografie van de geschiedenis van Gent 1994-1995', Handelingen der Maatschappij voor Geschiedenis en Oudheidkunde, Gent, XLIX, 1995, pp 283332.

\& A. De Schryver, M. Martens, 'Gand', in Enciclopedia dell' Arte Medievale, Roma, 6, 1995, pp. 460-474.

\& G. Everaert, D. Lievois, G. Stoops, 'Het huis 'de Inghel' aan de Graslei in Gent', Handelingen der Maatschappij voor Geschiedenis en Oudheidkunde, Gent, XLIX, 1995, pp. 121-176.

\& D. Lievois, 'Het Gouverneurshuis Vlasmarkt', in Open Monumentendag Gent 10 september 1995, pp. 28-31.

$\&$ D. Lievois, G. Stoops, Enkele nieuwe inzichten in de ontwikkeling van het Klein Begijnhof in Gent, in Verhandelingen der Maatschappij voor Geschiedenis en Oudheidkunde, Gent, 21, 1995, pp. 305-319.

\section{6}

'De monumentale refter van de Gentse Sint-Pietersabdij', 26e Kunst \& Antiekbeurs van Vlaanderen, Gent, 1996, pp. 6-9. 
'Woord, beeld en materie. Het Sint-Baafsdorp in Gent', in J. De Zutter, L. Charles \& A. Capiteyn, Qui valet ingenio. Liber amicorum Johan Decavele, Gent,1996, pp. 289-317.

(red.), 'Herdenking Joan Vandenhoute (1951-1981', Stadsarcheologie. Bodem en Monument in Gent, Gent, 20/4, 1996, pp. 5-14.

\& L. Charles, R. De Herdt, 'Bibliografie van de geschiedenis van Gent 1995-1996', Handelingen der Maatschappij voor Geschiedenis en Oudheidkunde, Gent, L, 1996, pp. 253-304.

\& D. Lievois, G. Stoops, G., 'Stenen kanonskogels in Gent. Omtrent een vondst aan het Kuipgat', Stadsarcheologie. Bodem en Monument in Gent, Gent, 20/4, 1996, pp. 15-42.

\& D. Lievois, G. Stoops, P. Swimberghe, 'Hollands porselein in Gent', Stadsarcheologie. Bodem en Monument in Gent, Gent, 20/3, 1996, pp. 5-55.

\section{7}

'Monastieke architectuur in Gent. Over Ganda en Blandinium', Vlaanderen, Tielt, 46/4, 1997, pp. 323-326.

'Het stenen verleden. Een beknopt overzicht van bouwactiviteiten, bouwkundige ontwikkeling en monastieke architectuur', in G. Declercq (red.), Ganda \& Blandinium. De Gentse abdijen van Sint-Pieters en Sint-Baafs, Gent, 1997, pp. 115-146.

'Strijd tegen concurrentie. Over aardewerk in het 17 de-eeuwse Vlaanderen', Vlaanderen, Tielt, 46/3, pp. 38-43.

\& D. Boncquet, G. Everaert, D. Lievois, G. Stoops, 'Het huis De Spiegel aan het Goudenleeuwplein. Archeologisch en bouwhistorisch onderzoek', Stadsarcheologie. Bodem en Monument in Gent, Gent, 21/3-4, 1997, pp. 11-55.

\& L. Charles, R. De Herdt, 'Bibliografie van de geschiedenis van Gent 1996-1997', Handelingen van de Maatschappij voor Geschiedenis en Oudheidkunde, Gent, LI, 1997, pp. 229281.

\& G. Everaert, D. Lievois, G. Stoops, 'Het Anatomisch Instituut in het Bijlokehospitaal te Gent', Stadsarcheologie. Bodem en Monument in Gent, Gent, 21/2, 1997, pp. 4-21.

\section{8}

'1350 jaar Gent. De Gentenaars en hun huizen', in Waar is de tijd, Zwolle, 6, 1998, pp. 130-151.

'De kaakslag van Jan Borluut: een keerpunt in de Gentse wooncultuur', Cultuur-Info, Gent, 11/5, 1998, pp. 2-7.

'Een kwarteeuw stadsarcheologie in Gent. Verleden, heden en toekomst', Stadsarcheologie. Bodem en Monument in Gent, Gent, 22/4, 1998, pp. 5-22.

\& L. Charles, 'Bibliografie van de geschiedenis van Gent 1997-1998', Handelingen der Maatschappij voor Geschiedenis en Oudheidkunde, Gent, LII, 1998, pp. 161-197. 
\& L. Charles, 'Geld en muntwezen in Gent', Stadsarcheologie. Bodem en Monument in Gent, Gent, 22/2, 1998, pp. 6-32.

\& H. Demiddele, A. Ervynck, G. Stoops, 'Van Cornaerd tot Korenmarkt. Kiezelwieren onthullen het verleden van een Gents plein', Stadsarcheologie. Bodem en Monumenten in Gent, Gent, 22/3, 1998, pp. 20-28.

\section{9}

'Enkele aspecten van stedelijke ontwikkeling in Gent: percelen, huizen en bewoners', in Rotterdam Papers, Rotterdam, 10, 1999, pp. 143-153.

'Hof van Ryhove', in Open Monumentendag. Via Europa. Reisverhalen in steen, Gent, 1999, pp. 17-18.

'Stadsarcheologie', in J. Art (red.), Hoe schrijf ik de geschiedenis van mijn gemeente. IV. Archeologie, Gent, 4, 1999, pp. 451-473.

$\&$ L. Bauters, G. Stoops, 'Sint-Baafskathedraal, archeologische begeleiding van een funderingsonderzoek', Monumentenzorg en cultuurpatrimonium. Jaarverslag van de provincie Oost-Vlaanderen 1998, Gent, 1999, pp. 94-96.

\& L. Charles, 'Bibliografie van de geschiedenis van Gent 1998-1999', Handelingen der Maatschappij voor Geschiedenis en Oudheidkunde, Gent, LIII, 1999, pp. 195-245.

\& A. Ervynck (red.), 'Het 'Zwarte Laag'-project. Ophogingslaag, straatvuil, baggerspecie, stort of composthoop? Datering, herkomst en betekenis van de 'zwarte laag' in Gent', Archaeologia Mediaevalis, Gent, 22, 1999, pp. 64-66.

\section{0}

'Espaces publics dans les villes flamandes au moyen âge: l'apport de l'archéologie urbaine', in M. Boone \& P. Stabel (eds), Shaping Urban Identity in Late Medieval Europe, Leuven-Apeldoorn, 2000, pp. 26-41.

'Histoire architecturale de la plus ancienne église de Gand', in B Bouckaert (dir.), La cathédrale de Saint-Bavon de Gand, du moyen âge au baroque, Gent-Paris, 2000, pp. 86-105.

'Mens en cultuur', in B De Muynck (red.), Stedelijk Natuurreservaat Bourgoyen-Ossemeersen, Gent, 2000, pp. 24-39.

"'Recent" en toch ook archeologie. Enkele aspecten van het onderzoek in Oost-Vlaanderen', $V O B O V$-Info, Dendermonde, 52, 2000, pp. 64-71.

'Het stenen verhaal van de oudste stadskerk van Gent', in B. Bouckaert (dir.), De SintBaafskathedraal in Gent, van Middeleeuwen tot Barok, Gent-Paris, 2000, pp. 86-105.

(dir.), Het prinselijk Hof ten Walle in Gent, Gent, 2000.

\& L. Charles, Bibliografie van de geschiedenis van Gent 1999-2000', Handelingen der Maatschappij voor Geschiedenis en Oudheidkunde, Gent, LIV, 2000, pp. 193-234. 
\& L. Delehouzee, J. De Meulemeester, J. Lemeunier, A. Matthys, M. Piavaux, Architecture romane en Belgique, Bruxelles, 2000.

\& L. Delehouzee, J. De Meulemeester, J. Lemeunier, A. Matthys, M. Piavaux, Romaanse architectuur in België, Tielt, 2000.

\& G. Everaert, F. Gelaude, M. Helskens, D. Laporte, G. Stoops, 'Tussen Wal en Hof, in M.C. Laleman (dir.), Het prinselijk Hof ten Walle in Gent, Gent, 2000, pp. 24-66.

\& G. Stoops, 'De Wal in de 13de en de 14de eeuw', in M.C. Laleman (dir.), Het prinselijk Hof ten Walle in Gent, Gent, 2000, pp. 13-24.

\section{1}

'Archéologie, iconographie et sources écrites: l'exemple de Gand', in Archéologie du bâtiment, appproche globale, (Actes des Journées d'Archéologie en Provincie de Liège, 5), Liège, 2001, pp. 29-40.

'Het prinselijk Hof ten Walle in Gent: recent onderzoek en nieuwe inzichten', Handelingen der Maatschappij voor Geschiedenis en Oudheidkunde, Gent, LV, 2001, pp. 199-236.

\& L. Charles, V. Meillander, 'Bibliografie van de geschiedenis van Gent 2000-2001', Handelingen der Maatschappij voor Geschiedenis en Oudheidkunde, Gent, LV, 2001, pp. $467-$ 523.

\& D. Lievois, A. Rambaut, 'De Heilig-Kruiskerk', in Grondstof, stof tot nadenken...Metaal. Open Monumentendag 2001, Gent, 2001, p. 29.

\section{2}

'Le Castrum Novum de Gand (Belgique)', in G. Blieck, P. Contamine, N. Faucherre \& J. Mesqui (dir.), Le château et la ville. Conjonction, opposition, juxtaposition (XIe-XVIIIe siècle), (Editions du CTHS), Paris, 2002, pp. 335-353.

'Het Gravensteen in Gent', in L. De Vos (dir.), Burchten en forten en andere versterkingen in Vlaanderen, Leuven, 2002, pp. 39-43.

'Het Rabot in Gent', in L. De Vos (dir.), Burchten en forten en andere versterkingen in Vlaanderen, Leuven, 2002, pp. 58-60.

\& L. Charles, G. Everaert, D. Lievois, 'Erf, huis en mens. Huizenonderzoek in Gent voor genealogen', Vlaamse Stam, Antwerpen, 38/10-11, 2002, pp. 509-536.

\& L. Charles, V. Meillander, 'Bibliografie van de geschiedenis van Gent 2001-2002', Handelingen der Maatschappij voor Geschiedenis en Oudheidkunde, Gent, LVI, 2002, pp. 299-334.

\& D. Lievois, 'De wetenschappelijke betekenis van Frans De Potters ' Gent. Van den oudsten tyd tot heden", in S. Meersseman, Gent van den oudsten tijd tot heden. Registers op 
het werk van Frans De Potter, (Verhandelingen der Maatschappij voor Geschiedenis en Oudheidkunde van Gent, 27), Gent, 2002, pp. 15-24.

\section{3}

Gent. Het 13de-eeuwse hospitaal van de Bijloke, (Erfgoedmemo, 2), Gent, 2003.

Gent. Het middeleeuwse Gravensteen, (Erfgoedmemo, 1), Gent, 2003.

Gent, een stad van Stenen, (Erfgoedmemo, 5), Gent, 2003.

'Het stenen Gent', in Open Monumentendag, Gent, 2003, pp. 2-7.

\& L. Charles, G. Everaert, D. Lievois, De Berg van Barmhartigheid in Gent, Gent, 2003.

\& L. Charles, V. Meillander, 'Bibliografie van de geschiedenis van Gent 2002-2003', Handelingen der Maatschappij voor Geschiedenis en Oudheidnkunde, Gent, LVII, 2003, pp. 279-321.

\section{4}

'Gentse klokken buiten het Gentse Beflort', Clocke Roeland. Nieuws van de Gentse Beiaardkring, Gent, 8/4, 2004, pp. 4-5.

'Onderzoek in het Gentse Prinsenhof, AVRA-Bulletin, Antwerpen, 4, 2004, pp. 21-34.

'De ontwikkeling van Blandinium', Handelingen der Maatschappij voor Geschiedenis en Oudheidkunde, Gent, LVIII, 2004, pp. 3-22.

'Témoins de basses-cours seigneuriales dans le tissu urbain d'une ville: l'exemple de Gent (Gand, Flandre Orientale, Belgique)', in Château Gaillard. Etudes de castellologie médiévale. La Basse-cour, (Publications CRAHM), Caen, 21, 2004, pp. 179-189.

$\&$ J. Baldewijns, 'Gent, hospitalen van de Bijloke', in Architectuur van Belgische hospitalen, (M \& L Cahier, 10), Brussel, 2004, pp. 152-155.

\& L. Charles, V. Meillander, 'Bibliografie van de geschiedenis van Gent 2003-2004', Handelingen der Maatschappij voor Geschiedenis en Oudheidkunde, Gent, LVIII, 2004, pp. 251-293.

\& H. Defoort (red.), 'Het STAM: een (ver)nieuw(end) stadsmuseum', in P. De Rynck (ed.), In situ. Stedelijkheid en Stadsmusea. Cities and City Museums, (Culturele Biografie Vlaanderen), Antwerpen, 2004, pp. 35-43.

\& B. Hillewaert, T. Vanderbeken, J. Veeckman, 'De stad in de CAI', in De opbouw van een archeologisch beleidsinstrument CAI, (IAP-Rapporten, 14), Brussel, 2004, pp. 59-67.

\section{5}

'Het centrum van een grote stad', in De Gentse Portus aan de Reep. Een historische verkenning, Gent, 2005, pp. 22-27. 
'De eerste middeleeuwse stad', in De Gentse Portus aan de Reep. Een historische verkenning, Gent, 2005, pp. 8-11.

'Een stad van Stenen', in De Gentse Portus aan de Reep. Een historische verkenning, Gent, 2005, pp. 12-14.

'Vergankelijk en duurzaam. Houtgebruik in Gent', in Hout grondstof, stof tot nadenken, (Open Monumentendag), Gent, 2005, pp. 12-25.

\& L. Charles, V. Meillander, 'Bibliografie van de geschiedenis van Gent 2004-2005', in Handelingen der Maatschappij voor Geschiedenis en Oudheidkunde, Gent, LIX, 2005, pp. 189-230.

$\&$ G. Stoops, Archeologisch onderzoek in de Gentse Bijloke, Vobov-Info, Dendermonde, 62, 2005, pp. 38-45.

\section{6}

'L'approche pluridisciplinaire d'une ville: Gent', in Mélanges d'archéologie médiévale. Liber amicorum en hommage à André Matthys, (Les Cahiers de l'Urbanisme, hors-série), Sprimont, 2006, pp. 112-121.

$\&$ B. Acke, G. Stoops, 'Mobiliteit van mensen, grondstoffen en kennis: het Hollandse porselein in het 17de-eeuwse Gent', in Import Export, (Open Monumentendag), Gent, 2006, pp. 36-45.

\& L. Charles, Het Gent boek, Gent-Zwolle, 2006.

\& L. Charles, V. Meillander, 'Bibliografie van de geschiedenis van Gent 2005-2006', Handelingen der Maatschappij voor Geschiedenis en Oudheidkunde te Gent, Gent, LX, 2006, pp. 393-445.

\& G. Stoops, 'Archeologisch onderzoek in de Bijlokesite te Gent (O.-Vl.)', Archaeologia Mediaevalis, Gent, 29, 2006, pp. 63-65.

\section{7}

'Het geheugen van een stad: drie decennia Gentse stadsarcheologie', $M$ \& L Monumenten, landschappen \& archeologie, Brussel, 26/2, 2007, pp. 6-23.

Gent. Middeleeuwse baksteenarchitectuur, (Erfgoedmemo, 27), Gent, 2007.

'Hôpitaux et hospitalité à Gand: l'apport de l'archéologie urbaine', in Hôpitaux du moyen âge et des temps modernes. Actes Archaeologia Mediaevalis 25, 14-15-16/03/2002, Bruxelles, 2007, pp. 81-90.

'Middeleeuwen. Wonen in Gent', in B. Baillieul (dir.), Stadsmussen onder dak. Wonen in Gent van de middeleeuwen tot 1914, (Stad Gent, Dienst Monumentenzorg), Gent, 2007, pp. 5-16. 
\& B. Acke, D. Lievois, P. Steurbaut, G. Stoops, R. Trommelmans, 'Bisdomplein', in Archeologisch onderzoek in Gent 1999-2006, (Stadsarcheologie. Bodem en monument in Gent, 2/1), Gent, 2007, pp. 17-34.

\& G. Antheunis, 'Materiële oorlogsbronnen in Gent', in L. Charles (red.), Buskruit en Sauerkraut. Oorlogsbronnen in De zwarte Doos (20ste eeuw), Gent, 2007, pp. 103-166.

\& A. Capiteyn, L. Charles, Historische atlas van Gent. Een visie op verleden en toekomst, (SUN/De Zwarte Doos), Amsterdam, 2007.

\& E. Raeymaekers, P. Steurbaut, 'Kantienberg, Sint-Pietersabdij, keermuur', in: Archeologisch onderzoek in Gent 1999-2006', (Stadsarcheologie. Bodem en Monument in Gent, 22/1), Gent, 2007, p. 55-58.

\& E. Raeymaekers, P. Steurbaut, G. Vermeiren, 'Mahatma Gandhistraat 30, Hoosmolen', in Archeologisch onderzoek in Gent 1999-2006, (Stadsarcheologie. Bodem en Monument in Gent,2/1), Gent, 2007, pp. 83-87.

\section{8}

"Château et pouvoir'. Beschouwingen bij symboolarchitectuur in de ontwikkelingen van het middeleeuwse Gent', Handelingen der Maatschappij voor Geschiedenis en oudheidkunde, Gent, LXII/1, 2008, pp. 5-42.

Gent. Stenen zuilen, (Erfgoedmemo, 33), Gent, 2008.

\& L. Charles, D. Lievois, P. Steurbaut, Van walsites en speelhoven. Het Vrije van Gent bij Jacques Horenbault (1619), Gent, 2008.

\& V. Meillander, 'Bibliografie van de geschiedenis van Gent 2007-2008', Handelingen der Maatschappij voor Geschiedenis en Oudheidkunde, Gent, LXII/2, 2008, pp. 349-409.

\& G. Stoops, 'Baksteengebruik in Vlaamse steden. Gent in de middeleeuwen', in T. Coomans \& H. van Royen (eds), Brick Architecture in Flanders and Northern Europe: the question of the Cistercian Origin. Middeleeuwse baksteenarchitectuur in Vlaanderen en Noord-Europa, (Novi Monasterii, 7), Koksijde, 2008, pp. 163-183.

\section{9}

'Armand Heins: een 'artiste-peintre' met archeologische blik', in R. De Herdt (red.), Armand Heins. Etser, lithograaf en drukker, Gent, 2009, pp.196-215.

'Graslei: laatmiddeleeuwse sculpturen', in Archeologisch onderzoek in Gent 2000-2009, (Stadsarcheologie. Bodem en Monument in Gent, 2/3), Gent, 2009, pp. 13-21.

'Nabeschouwingen', in Onder het Sint-Pietersplein. Van hoogadellijke begraafplaats tot parking, Gent, 2009, pp. 134-138.

\& M.A. Bru, G. Vermeiren, 'Het grafveld van het atrium', in Onder het Sint-Pietersplein. Van hoogadellijke begraafplaats tot parking, Gent, 2009, pp. 64-75. 
\& M.A. Bru, G. Vermeiren, 'Graven in de monnikenkerk', in Onder het Sint-Pietersplein. Van hoogadellijke begraafplaats tot parking, Gent, 2009, pp. 76-87.

\& M.A. Bru, G. Vermeiren, 'Monnikenkerk en atrium', in: Onder het Sint-Pietersplein. Van hoogadellijke begraafplaats tot parking, Gent, 2009, pp. 34-63.

\& M.A. Bru, G. Vermeiren, 'Opgravingen op het Sint-Pietersplein', in Onder het Sint-Pietersplein. Van hoogadellijke begraafplaats tot parking, Gent, 2009, pp. 10-25.

\& M.A. Bru, G. Vermeiren, 'Ouder dan kerk en atrium', in Onder het Sint-Pietersplein. Van hoogadellijke begraafplaats tot parking, Gent, 2009, pp. 26-33.

\& L. Charles, V. Meillander, 'Bibliografie van de geschiedenis van Gent, 2008-2009', Handelingen der Maatschappij voor Geschiedenis en Oudheidkunde, Gent, XLIII/2, 2009, pp. 267-353.

\& V. Cnudde, J. Dewanckele, M. De Ceukelaire, G. Everaert, P. Jacobs (red.), Gent... Steengoed!, (Academia Press), Gent, 2009.

\& V. Cnudde, J. Dewanckele, M. De Ceukelaire, G. Everaert, P. Jacobs (red.), Gent... Steenroute, (Academia Press), Gent, 2009.

\& E. Raeymaekers, P. Steurbaut, G. Stoops, 'Nederpolder 4', in Archeologisch onderzoek in Gent 2000-2009, (Stadsarcheologie. Bodem en Monument in Gent, 2/3), Gent, 2009, pp. 34-39.

\section{0}

'De Domus Comitis van het Gentse Gravensteen', in M. Dewilde, A; Ervynck \& F. Becuwe (red.), Cenulae recens factae. Een huldeboek voor John De Meulemeester, (Novi Monasterii, 10), Koksijde, 2010, pp. 227-254.

Gent. Meulestede, (Erfgoedmemo, 45), Gent, 2010.

'Gent: de ontwikkeling van een stad aan de samenvloeiing van Leie en Schelde', in C. Deligne \& T. Soens (red.), Steden en Water, (Jaarboek Ecologische Geschiedenis), Gent, 2010, pp. 9-32.

'Le plan de Gand peint par Jacques Horenbault en 1619 et l'inventaire de sites fossoyés', in Château Gaillard, Caen, 24, 2010, pp. 159-163.

'Sint-Pietersplein: de Onze-Lieve-Vrouwekerk', in Archeologisch onderzoek in Gent 20022010, (Stadsarcheologie. Bodem en Monument in Gent, 2/4), Gent, 2010, pp. 121-156.

Een stad vandaag: resultaat van hoe de mens steeds meer greep kreeg op de vier elementen, (Website Open Monumentendag Vlaanderen), Brussel, 2010, 4 blz.

'Het stenen patrimonium van Gent: een verhaal van vermogen en onvermogen', Jaarboek Abdijmuseum Ten Duinen 1138, (Novi Monasterii, 9), Koksijde, 2010, pp. 21-36. 
\& G. Antheunis, P. Steurbaut, 'Koning Leopold II-laan 99-103', in Archeologisch onderzoek in Gent 2002-2010, (Stadsarcheologie. Bodem en Monument in Gent, 2/4), Gent, 2010, pp. 56-59.

\& M. Berkers, M. Gernay, P. Steurbaut, 'Gentbrugge, Guldenmeers 15', in Archeologisch onderzoek in Gent 2002-2010, (Stadsarcheologie. Bodem en Monument in Gent, 2/4), Gent, 2010, pp. 201-207.

\& M.A. Bru, A. Ervynck, D. Gaublomme, D. Lievois, G. Vermeiren, 'Een stenen vogel: een uniek 'monument' in de Gentse Sint-Pietersabdij', $M$ \& L Monumenten, landschappen en archeologie, Brussel, 29/3, 2010, pp. 4-26.

\& M.A. Bru, D. Lievois, P. Steurbaut, G. Vermeiren., 'Sint-Veerleplein 5, Oude Vismijn: grafplaat van 1567', in Archeologisch onderzoek in Gent 2002-2010, (Stadsarcheologie. Bodem en Monument in Gent, 2/4), Gent, 2010, pp. 163-168.

\& G. De Clercq, 'Archaeology of the urban space', in M. Boone \& G. Deneckere (red.), Ghent. A City of All Times, Brussels-Ghent, 2010, pp. 18-49.

\& G. De Clercq, 'Archéologie de l'espace urbain', in M. Boone \& G. Deneckere (red.), Gand. Ville de tous les temps, Bruxelles-Gand, 2010, pp. 18-49.

\& G. De Clercq, 'Archeologie van de stedelijke ruimte', in M. Boone \& G. Deneckere (red.), Gent, stad van alle tijden, Brussel, Gent, 2010, pp. 18-49.

\& E. Raeymaekers, P. Steurbaut, 'Biezekapelstraat 2', in Archeologisch onderzoek in Gent 2002-2010, (Stadsarcheologie. Bodem en Monument in Gent, 2/4), Gent, 2010, pp. 12 17.

\& G. Vermeiren, 'Ruimte en bewoning in het centrum van het middeleeuwse Gent', Handelingen der Maatschappij voor Geschiedenis \& Oudheidkunde te Gent, Gent, 64/1, 2010, pp. 3-56.

\section{1}

'Sint-Pietersplein, de abthuizen van de Sint-Pietersabdij', in Archeologisch onderzoek in Gent 2002-2011, (Stadsarcheologie. Bodem en Monument in Gent, 2/5, Gent, 2011, pp. 108-141.

\& M. Berkers, 'Vooruitstrevend of ouderwets? Het Gravensteen als spiegel voor het ontstaan van het kasteel in het middeleeuwse graafschap Vlaanderen', Handelingen der Maatschappij voor Geschiedenis en oudheidkunde, Gent, 65/1-2, 2011, pp. 5-41.

\& D. Lievois, 'Prinsenhof 22', in Archeologisch onderzoek in Gent 2002-2011, (Stadsarcheologie. Bodem en Monument in Gent, 2/5), Gent, 2011, pp. 41-44. 


\section{2}

'Archeologie in de stad van vandaag: reden tot conflict?', in Dienst Monumentenzorg en Architectuur stelt voor in 20125 lezingen, Gent, 2012, pp. 52-61.

'Sint-Pietersplein 9-15, Sint-Pietersabdij: grafkelders in de kruisgang', in Archeologisch onderzoek in Gent 2012, (Stadsarcheologie. Bodem en Monument in Gent, 2/6), Gent, 2012, pp. 155-214.

\& A. Ervynck, M. Berkers, 'Sint-Veerleplein 11, Gravensteen: bewerkt bot en gewei', in Archeologisch onderzoek in Gent 2012, (Stadsarcheologie. Bodem en Monument in Gent, 2/6), Gent, 2012, pp. 215-236.

$\&$ G. Vermeiren, 'Stenen en water op de centrumpleinen', e-Heraut, Gent, 2/1, 2012, pp. 3-5.

\section{3}

'De 'archeologische beweging' in de aanloop naar 1913', in Impact. Wereldtentoonstelling Gent 1913, Gent, 2013, pp. 52-69.

'Middeleeuws vensterglas in Gent (Oost-Vlaanderen, België)', Jaarboek Abdijmuseum Ten Duinen, (Novi Monasterii, 13), Koksijde, 2013, pp. 147-152.

(dir.), Ontdek de Bijloke Gent. Geschiedenis. Architectuur. Cultuur, Gent, 2010-2013.

\section{4}

Bodemverhalen: 40 jaar archeologisch stadsonderzoek in Gent, Handelingen der Maatschappij voor Geschiedenis en Oudheidkunde, Gent, 68, 2014, pp. 7-48.

Gent. Laatmiddeleeuwse tegelvloeren, (Erfgoedmemo, 71), Gent, 2014.

'De graven van Vlaanderen en hun Gentse residentie', Westerheem, Vlaardingen, speciaal 3, 2014, pp. 260-268.

(dir.), Honderdsteboven, 100 archeologische beelden uit Gent, Gent, 2014.

(red.), 'Het Panoramisch Gezicht op Gent 1534', Handelingen der Maatschappij voor Geschiedenis en Oudheidkunde, Gent, 68, 2014, pp. 165-207.

$\& \mathrm{~F}$. Newham (dir.), Shared experience in the conservation and presentation of heritage assets, (Portico), Chester, 2014.

\section{5}

'De Abrahamstraat. Berg van Barmhartigheid. Van Gratiskas tot caritas', in R. Mantels, A.L. Van Bruaene, C. Verbruggen \& G. Deneckere, Geloven in Gent. Plaatsen van het religieuze verleden, Gent, 2015, pp. 246-252. 
'De Bijloke. Oord van zusterlijke ziekenzorg', in R. Mantels, A.L. Van Bruaene, C. Verbruggen \& G. Deneckere, Geloven in Gent. Plaatsen van het religieuze verleden, Gent, 2015, pp. 208-213.

'De stad als archeologische opdracht', Archaeologia Mediaevalis, Gent, 38, 2015, pp. 9-10.

(dir.), Kleurrijk - Wynantz \& Gent omstreeks 1820, Gent, 2015.

\& G. Vermeiren, M.A. Bru, P. Steurbaut, G. Stoops, 'Werfcontroles in de Kapittelstraat (O.-Vl.)', Archaeologia Mediaevalis, Gent, 38, 2015, pp. 196-198.

\& G. Vermeiren, G. Stoops, M.A. Bru, 'Information to die for. 40 jaar stadsarcheologie Gent: dood en begrafenis in een ruimere context', Jaarboek Abdijmuseum Ten Duinen, (Novi Monasterii, 15), Koksijde, 2015, pp. 83-88.

\section{6}

'De draak als waakzame hoeder over Gent', in P. Nissen \& S. Verdonck, Draken. Beesten van verbeelding, Nijmegen, 2016, pp. 94-99.

'Ghent (East Flanders, Belgium) in the Discussion about Early Towns and Artisan Production', $M$ \& MM. Medieval and Modern Matters, Turnhout, 4, 2013-2016, pp. 109-118.

\& G. De Clercq, 'Archeologie van de stedelijke ruimte', in M. Boone \& G. Deneckere (red.), Gent, stad van alle tijden, Brussel, Gent, 2016², pp. 18-49.

\section{7}

Cisterciënzerdomeinen ten noorden van Gent: over hun ontstaan in de 13de eeuw, hun lokalisatie, hun bestaan en hun sociaaleconomische betekenis voor de Gentse agglomeratie, Handelingen der Maatschappij voor Geschiedenis en Oudheidkunde van Gent, Gent, LXXXI, 2017, pp. 7-55.

Gent. Een Spaans Kasteel?, (Erfgoedmemo, 90), Gent, 2017.

\section{8}

'Een bocht in de rivier. De Huidevettershoek in Gent', in G. Vermeiren, M.A. Bru \& A. Ervynck (red.), De Krook. Een leerrijk boek, Gent, 2018, pp. 24-39.

'Het Spaans Kasteel in de 16de eeuw', in Het Spaans Kasteel Gent. Van dwangburcht tot woonwijk, Gent, 2018, pp. 16-51.

'Touches rouges dans le paysage du comté de Flandre', in Château Gaillard 28. Etudes de castellologie médiévale. L'environnement du château, Caen, 2018, pp. 183-190.

'De zwanenzang van een Citadel', in Het Spaans Kasteel Gent. Van dwangburcht tot woonwijk, Gent, 2018, pp. 172-203. 
\& L. Devriese, 'De Gouverneurswoning?', in Het Spaans Kasteel Gent. Van dwangburcht tot woonwijk, Gent, 2018, pp. 162-171.

\& G. Stoops, 'De doden van het Nieuw Kasteel', in Het Spaans Kasteel Gent. Van dwangburcht tot woonwijk, Gent, 2018, pp. 120-125.

\section{Recensies}

'Maria van Bourgondië, Brugge. Een archeologisch-historisch onderzoek in de Onze-LieveVrouwekerk, (recensie)', 't Profiel, Gent, 3/5, 1982, pp. 4-5.

'Recensie Jean-Louis Van Belle, Dictionnaire des signes lapidaires, Belgique et Nord de la France', Oostvlaamse Zanten, Gent, 60/2, 1985, pp. 118-120.

'Recensie: VERHULST, A., Het ontstaan van de steden in Noordwest-Europa: een poging tot verklarende synthese', Stadsarcheologie. Bodem en Monument in Gent, Gent, 11/3, 1987, pp. 1-15.

'Recensie: GYSSELING, M., Uit de vroege geschiedenis van Gent en de Oost-Oudburg, in Jaarboek De Oost-Oudburg, Gent, 1986', Stadsarcheologie. Bodem en Monument in Gent, Gent, 12/2, 1988, pp. 26-29.

'Recensie: Farmacie te Gent', Stadsarcheologie. Bodem en Monument in Gent, Gent, 15/2, 1991, pp. 38-42.

'Recensie: Verborgen Steden', Stadsarcheologie. Bodem en Monument, Gent, 15/4, 1991, pp. 46-49.

'Recensie: Romaanse architectuur in België', Stadsarcheologie. Bodem en Monument, Gent, 16/3, 1992, pp. 44-46.

\section{Kroniek-, tentoonstellings- en voordrachtteksten}

\section{7}

'Oude bodemvondsten: een tegelvloer van de 14de-15de eeuw', Stadsarcheologie, Gent, 1/1, 1977 , pp. 42-43.

\section{8}

\& J. Vandenhoute, B. Baillieul, R. Van de Walle, De Mageleinstraat. Een historisch evocatie, Gent, 1978.

\section{0}

'Van grafelijke burcht tot fabriek', in 800 jaar Gravensteen, Gent, 1980, pp. 13-18. 


\section{1}

'Gent, Stadsarcheologie', Archeologie, Brussel, 1, 1981, pp. 4-5.

'Groentenmarkt 7, Vleeshuis', in Stadsarcheologie, Gent, 5/1, 1981, pp. 43-44.

'Nieuwe Wandeling', Stadsarcheologie, Gent, 5/3, 1981, pp. 31-32.

'Trommelstraat, Karmelietenklooster, Infirmerie', Stadsarcheologie, Gent, 5/3, 1981, pp. 33-34.

'Vrijdagmarkt', Stadsarcheologie, Gent, 5/3, 1981, p. 35.

'Wondelgem, Kouterstraat', Stadsarcheologie, Gent, 5/3, 1981, p. 36.

\& G. Deseyn,' Begijnhoflaan', Stadsarcheologie, Gent, 5/2, 1981, p. 37.

\& R. Van de Walle, 'Vrijdagmarkt', Stadsarcheologie, Gent, 5/2, 1981, p. 39.

\section{2}

'De oudste stenen burgerwoningen in Gent', in Programmaboek XLVIe Kongres van de Federatie van Kringen voor Oudheidkunde en Geschiedenis van België, Hasselt, 1982, p. 50.

'Puinstraat', Stadsarcheologie, Gent, 6/2, 1982, p. 47.

'Schoolkaai', Stadsarcheologie, Gent, 6/2, 1982, pp. 47-48.

'Sint-Denijs-Westrem, Putstraat 20', Stadsarcheologie, Gent, 6/2, 1982, p. 50.

'Trommelstraat, Karmelietenklooster', Stadsarcheologie, Gent, 6/2, 1982, pp. 48-49.

'Trommelstraat, Karmelietenklooster', Stadsarcheologie, Gent, 6/3, 1982, p. 40.

'Villard de Honnecourt', 't Profiel, Gent, 3/4, 1982, pp. 2-3.

'Vrijdagmarkt 34-35, Het Toreken', Stadsarcheologie, Gent, 6/1, 1982, pp. 50-51.

\& P. Raveschot, 'Onderbergen 1-11, Dominicanerklooster', Stadsarcheologie, Gent, 6/2, 1982, pp. 46-47.

\& P. Raveschot,' Drongen, een middeleeuwse mote’, Dronghine, Drongen, 1982, pp. 47-48.

\& J. Vandenhoute, 'Stadsarcheologie in Gent', Archaeologia Mediaevalis, Brussel, 5, 1982, pp. $48-49$.

\section{3}

'Gentse stenen woningen "hoog als torens”', G.O.V.-Heraut, Gent, 18/1, 1983, pp. 4-5.

'Justus de Harduwijnlaan 49', Stadsarcheologie, Gent, 7/2, 1983, p. 36.

'Kantienberg, Sint-Pietersabdij', Stadsarcheologie, Gent, 7/1, 1983, pp. 48-49.

'Trommelstraat, Karmelietenklooster', Stadsarcheologie, Gent, 7/2, 1983, p. 40.

'Universiteitsstraat 8', Stadsarcheologie, Gent, 7/2? 1983, p. 43.

'Wellinckstraat 103', Stadsarcheologie, Gent, 7/2, 1983, pp. 44-45. 
\& P. Raveschot, 'Drongenhof, Stadsarchelogie, Gent, 7/3, 1983, p. 32.

\& P. Raveschot,' Gent', Archeologie, Brussel, 2, 1983, p. 117.

\& P. Raveschot, 'Gent (O.VL.): stadsarcheologisch onderzoek', Archeologie, Brussel, 1, 1983, pp. 31-32.

\& P. Raveschot, 'Kasteellaan', Stadsarcheologie, Gent, 7/3, 1983, p. 34.

\& P. Raveschot, 'Pekelharing', Stadsarcheologie, Gent, 7/3, 1983, p. 35.

\& P. Raveschot,' Sint-Veerleplein 11, Gravensteen', Stadsarcheologie, Gent, 7/3, 1983, pp. 35-36.

\& P. Raveschot, 'Tempelhof, Stadsarcheologie, Gent, 7/2, 1983, pp. 39-40.

\& P. Raveschot, 'Wilderoosstraat 13', Stadsarcheologie, Gent, 7/3, 1983, p. 36.

\& P. Raveschot, 'Zandpoortstraat 45', Stadsarcheologie, Gent, 7/3, 1983, pp. 36-37.

$\&$ R. Van de Walle, 'Stadsarcheologie in Gent (O.VL.)', Archaeologia Mediaevalis, Namur, 6, 1983, pp. 46-48.

\section{4}

Bodem en gebouw in het teken van de stadsgeschiedenis. Kennismaking met de Gentse stadsarcheologie, (Stichting Lodewijk de Raet), Gent, 1984.

'Trommelstraat, Karmelietenklooster', Stadsarcheologie, Gent, 8/1, 1984, p. 70.

\& P. Raveschot, 'Gent (O.VL.): archeologisch onderzoek', Archeologie, Brussel, 2, 1984, pp. 17-18.

\& P. Raveschot, 'Veldstraat 57-59', Stadsarcheologie, Gent, 8/2, 1984, p. 43.

\section{5}

'Lange Steenstraat', Stadsarcheologie. Bodem en Monument in Gent, Gent, 9/1, 1985, pp. $48-49$.

'Lange Steenstraat', Stadsarcheologie. Bodem en Monument in Gent, Gent, 9/3, 1985, pp. $41-42$.

'Prooststraat, Gouverneurswoning', Stadsarcheologie. Bodem en Monument in Gent, Gent, $9 / 1,1985$, p. 50.

'Prooststraat, Gouverneurswoning', Stadsarcheologie. Bodem en Monument in Gent, Gent, 9/2, 1985 , p. 60.

Saint-Omer, Archeologie, Brussel, 2, 1985, p. 83.

\& P. Raveschot, 'Gent (O.Vl.): stadsarcheologisch onderzoek', Archeologie, Brussel, 2, 1985, pp. 114-115. 
\& P. Raveschot, 'Stadsarcheologisch onderzoek in Gent', Archaeologia Mediaevalis, Brussel, 8, 1985, pp. 72-73.

\& P. Raveschot, P. Swimberghe, 'Gent (O.Vl.): stadsarcheologisch onderzoek', Archeologie, Brussel, 1, 1985, pp. 14-15.

\& P. Raveschot, P. Swimberghe, 'Goudenleeuwplein', Stadsarcheologie. Bodem en Monument in Gent, Gent, 9/3, 1985, pp. 38-39.

\& P. Raveschot, P. Swimberghe, 'Sint-Pietersnieuwstraat', Stadsarcheologie. Bodem en Monument in Gent, Gent, 9/3, 1985, pp. 41-42.

\& P. Raveschot, P. Swimberghe, 'Sint-Pietersplein', Stadsarcheologie. Bodem en Monument in Gent, Gent, 9/1, 1985, pp. 50-51.

\& P. Raveschot, P. Swimberghe, 'Goudenleeuwplein-Hoogpoort-Stadhuissteeg', Stadsarcheologie. Bodem en Monument in Gent, Gent, 9/2, 1985, pp. 52-53.

\section{6}

'Archeologie en monumentenzorg', in Programma XLVIIIste Kongres van de Federatie van Kringen voor Oudheidkunde en Geschiedenis van België, Kortrijk, 1986, p. 82.

'De Karmelietenkerk in Gent', Archaeologia Mediaevalis, Namur, 9, 1986, p. 56.

'Korenmarkt, Sint-Niklaaskerk', Stadsarcheologie. Bodem en Monument in Gent, Gent, 10/1, 1986, pp. 37-38; 10/2, pp. 74-76; 10/3, p. 39.

'Merelbeke, Koningin Fabiolapark', Stadsarcheologie. Bodem en Monument in Gent, Gent, 10/3, 1986, pp. 48-49.

'De Sint-Pietersabdij: een boeiend hoofdstuk uit de Gentse geschiedenis', Balista, Gent, 1/2, 1986, pp. 1-6.

'Tegels met tinglazuur uit Gent', Archaeologia Mediaevalis, Namur, 9, 1986, p. 58.

'Voor de huidenvetters hun Toreken bouwden...', in Het Toreken: uitzicht-inzicht, Gent, 1986, pp. 1-2.

'Zandberg 5-6', Stadsarcheologie. Bodem en Monument in Gent, Gent, 10/3, 1986, p. 45.

\& G. Everaert, P. Raveschot, 'Lange Steenstraat, Karmelietenkerk', Stadsarcheologie. Bodem en Monument in Gent, Gent, 10/2, 1986, p. 76.

\& G. Everaert, P. Raveschot, 'Onderstraat, Ryhovesteen', Stadsarcheologie. Bodem en Monument in Gent, Gent, 10/1, 1986, pp. 41-43.

\& G. Everaert, P. Raveschot, 'Onderstraat, Ryhovesteen', Stadsarcheologie. Bodem en Monument in Gent, Gent, 10/3, 1986, pp. 40-41.

\& P. Raveschot, 'Gent (O.VL.): Stadsarcheologisch onderzoek', Archeologie, Brussel, 1, 1986, p. 16. 
\& P. Raveschot, 'Hertogstraat 7', in: Stadsarcheologie. Bodem en Monument in Gent, Gent, 10/2, 1986, pp. 73-74.

\& P. Raveschot, 'Middeleeuwse bewoning langs de Gentse Hoogpoort', in Programma XLVIIIste Kongres van de Federatie van Kringen voor Oudheidkunde en Geschiedenis van Belgie, Kortrijk, 1986, pp. 69-70.

\& P. Raveschot, 'Stadsarcheologisch onderzoek in Gent', Archaeologia Mediaevalis, Namur, 9, 1986, pp. 58-61.

\& P. Raveschot, P. Swimberghe, Tussen Leie en Schelde... Een bouwkundig-historische wandeling langsheen de Hoogpoort, Gent, 1986.

\section{7}

'Archeologisch onderzoek aan het Drongenhof, in A. Rambaut, De gewezen refuge van de Drongense norbertijnen in het Gentse Patershol, Gent, 1987, p. 16.

'Sint-Pietersplein, Sint-Pietersabdij', Stadsarcheologie. Bodem en Monument in Gent, Gent, $11 / 1,1987$, p. 31.

'Sint-Veerleplein, Gravensteen', Stadsarcheologie. Bodem en Monument in Gent, Gent, $11 / 3,1987$, pp. 26-27.

'Zuivelbrugstraat, Zuivelbrug', Stadsarcheologie. Bodem en Monument in Gent, Gent, 11/3, 1987, pp. 27-28.

\& E. Cuypers, P. Raveschot, 'Schepenhuisstraat', Stadsarcheologie. Bodem en Monument in Gent, Gent, 11/1, 1987, p. 29.

\& P. Raveschot, 'Gandastraat', in: Stadsarcheologie. Bodem en Monument in Gent, Gent, 11/3, 1987, p. 17.

\& P. Raveschot, 'Gent (O.L.V.): Stadsarcheologisch onderzoek', Archeologie, Brussel, 2, 1987, pp. 132-134.

\& P. Raveschot, 'Gouvernementstraat 30-32', Stadsarcheologie. Bodem en Monument in Gent, Gent, 11/3, 1987, pp. 17-19.

\& P. Raveschot, 'Onderstraat 20, Ryhovesteen', Stadsarcheologie. Bodem en Monument in Gent, Gent, 11/3, 1987, p. 22.

\& P. Raveschot, 'Onderstraat 22, Ryhovesteen', Stadsarcheologie. Bodem en Monument in Gent, Gent, 11/1, 1987, p. 29.

\& P. Raveschot, 'Schepenhuisstraat', Stadsarcheologie. Bodem en Monument in Gent, Gent, 11/3, 1987, pp. 24-25.

\& P. Raveschot, 'Sint-Pietersplein, O.L.V. Sint-Pieterskerk', Stadsarcheologie. Bodem en Monument in Gent, Gent, 11/1, 1987, pp. 30-31.

\& P. Raveschot, 'Stadsarcheologisch onderzoek in Gent (O.VL.)', Archaeologia Mediaevalis, Gent, 10, 1987, pp. 55-56. 
\& P. Raveschot, 'Zwarte Katstraat 6-8', in: Stadsarcheologie. Bodem en Monument in Gent, Gent, 11/3, 1987, p. 28.

\section{8}

Archeologie in functie van restauratie en conservatie, (Postgraduaat Monumentenzorg I.C.R.), Gent, 1988.

'Kalversteeg', Stadsarcheologie. Bodem en Monument in Gent, Gent, 12/1, 1988, pp. 27-29.

'Korenmarkt, Sint-Niklaaskerk', Stadsarcheologie. Bodem en Monument in Gent, Gent, 12/4, 1988, pp. 46-48.

'Kraanlei', Stadsarcheologie. Bodem en Monument in Gent, Gent, 12/2, 1988, p. 37.

'Maaseik', Archeologie, Brussel, 2, 1988, p. 121.

'Poel, Torrepoort', Stadsarcheologie. Bodem en Monument in Gent, Gent, 12/2, 1988, pp. 39-40.

\& G. Everaert, L. Goossens, R. Van Nieuwenborgh, 'Drongenhof, Kapel', Stadsarcheologie. Bodem en Monument in Gent, Gent, 12/2, 1988, p. 31.

\& G. Everaert, P. Raveschot, 'Onderstraat 20-22, Ryhovesteen', Stadsarcheologie. Bodem en Monument in Gent, Gent, 12/2, 1988, pp. 40-44.

\& P. Raveschot, 'Emile Braunplein', Stadsarcheologie. Bodem en Monument in Gent, Gent, 12/4, 1988, p. 41.

\& P. Raveschot, 'Gent (O.Vl.): stadsarcheologisch onderzoek', Archeologie, Brussel, 1, 1988, pp. 31-32.

\& P. Raveschot, 'Gent (O. Vl.): stadsarcheologisch onderzoek', Archeologie, Brussel, 2, 1988, pp. 147-148.

\& P. Raveschot, 'Hoogpoort 2-4', Stadsarcheologie. Bodem en Monument in Gent, Gent, 12/2, 1988, pp. 33-35.

\& P. Raveschot, 'Onderstraat 59', Stadsarcheologie. Bodem en Monument in Gent, Gent, 12/2, 1988, p. 44.

\& P. Raveschot, 'Poel 7', Stadsarcheologie. Bodem en Monument in Gent, Gent, 12/4, 1988, pp. 49-50.

\& P. Raveschot, 'De Sint-Baafsabdij in Gent', Archaeologia Mediaevalis, Brussel, 11, 1988, pp. 46-47.

\& P. Raveschot, 'Stadsarcheologisch onderzoek in Gent', Archaeologia Mediaevalis, Brussel, 11, 1988, pp. 65-67.

\& P. Raveschot, 'Vrijdagmarkt 25, Lakenmetershuis', Stadsarcheologie. Bodem en Monument in Gent, Gent, 12/4, 1988, pp. 52-53. 


\section{9}

'Kammerstraat 4', Stadsarcheologie. Bodem en Monument in Gent, Gent, 13/4, 1989, p. 20.

\& D. Callebaut, P. Raveschot, 'Sint-Veerleplein, Gravensteen', Stadsarcheologie. Bodem en Monument in Gent, Gent, 13/4, 1989, p. 28.

$\&$ G. Everaert, D. Lievois, 'Onderstraat 10', Stadsarcheologie. Bodem en Monument in Gent, Gent, 13/4, 1989, pp. 24-25.

\& G. Everaert, P. Raveschot, R. Van Nieuwenborgh, 'Cataloniëstraat 1', Stadsarcheologie. Bodem en Monument in Gent, Gent, 13/4, 1989, pp. 12-15.

\& P. Raveschot, 'Drongenhof, Kapel', Stadsarcheologie. Bodem en Monument in Gent, Gent, 13/4, 1989, p. 17.

\& P. Raveschot, 'Groentenmarkt, Vleeshuis', Stadsarcheologie. Bodem en Monument in Gent, Gent, 13/4, 1989, pp. 17-18.

\& P. Raveschot, 'Hoogpoort 60', Stadsarcheologie. Bodem en Monument in Gent, Gent, 13/4, 1989, pp. 18-19.

\& P. Raveschot, 'Jan Breydelstraat 3-5', Stadsarcheologie. Bodem en Monument in Gent, Gent, 13/4, 1989, pp. 19-20.

\& P. Raveschot, 'Koningstraat 12', Stadsarcheologie. Bodem en Monument in Gent, Gent, 13/4, 1989, pp. 20-21.

\& P. Raveschot, 'Nodenaysteeg', Stadsarcheologie. Bodem en Monument in Gent, Gent, 13/4, 1989, pp. 23-24.

\& P. Raveschot, 'Onderstraat 28', Stadsarcheologie. Bodem en Monument in Gent, Gent, 13/4, 1989, p. 25.

\& P. Raveschot, 'Sint-Baafsplein 10', Stadsarcheologie. Bodem en Monument in Gent, Gent, 13/4, 1989, p. 28.

\& P. Raveschot, 'Speldenstraat 1', Stadsarcheologie. Bodem en Monument in Gent, Gent, 13/4, 1989, pp. 29-30.

\& P. Raveschot, 'Stadsarcheologisch onderzoek in Gent (O.-Vl.)', Archaeologia Mediaevalis, Namur, 12, 1989, pp. 57-59.

\& P. Raveschot, 'Vrijdagmarkt 9', Stadsarcheologie. Bodem en Monument in Gent, Gent, $13 / 4,1989$, p. 30.

\section{0}

'Korenmarkt, Sint-Niklaaskerk', Stadsarcheologie. Bodem en Monument in Gent, Gent, 14/3, 1990, pp. 52-53.

'Onderbergen 86', Stadsarcheologie. Bodem en Monument in Gent, Gent, 14/2, 1990, pp. 52-53. 
\& D. Boncquet, 'Goudstraat 12', Stadsarcheologie. Bodem en Monument in Gent, Gent, 14/2, 1990, pp. 51-52.

\& D. Callebaut, P. Raveschot, 'Onderzoek van het Gravensteen in Gent (O. Vl.)', Archaeologia Mediaevalis, Gent, 13, 1990, pp. 48-50.

\& P. Raveschot, 'Bijlokekaai, Ziekenzaal', Stadsarcheologie. Bodem en Monument in Gent, Gent, 14/1, 1990, pp. 54-55.

\& P. Raveschot, 'Bijlokekaai, Ziekenzaal', Stadsarcheologie. Bodem en Monument in Gent, Gent, 14/2, 1990, pp. 49-51.

\& P. Raveschot, 'Godshuizenlaan', Stadsarcheologie. Bodem en Monument in Gent, Gent, 14/1, 1990, pp. 55-56.

\& P. Raveschot, 'Korte Kruisstraat 4-8/ Lange Kruisstraat 8-10', Stadsarcheologie. Bodem en Monument in Gent, Gent, 14/4, 1990, pp. 96-97.

\& P. Raveschot, 'Kortrijksesteenweg 14-30', Stadsarcheologie. Bodem en Monument in Gent, Gent, 14/3, 1990, p. 53.

\& P. Raveschot, 'Kouter 172', Stadsarcheologie. Bodem en Monument in Gent, Gent, 14/1, 1990, pp. 55-56.

\& P. Raveschot, 'Prinsenhof-Bachtenwalle', Stadsarcheologie. Bodem en Monument in Gent, Gent, 14/2, 1990, pp. 53-54.

\& P. Raveschot, 'Sint-Veerleplein 11, Gravensteen', Stadsarcheologie. Bodem en Monument in Gent, Gent, 14/2, 1990, p. 55.

\& P. Raveschot, 'Stadsarcheologisch onderzoek te Gent (O. Vl.)', Archaeologia Mediaevalis, Gent, 13, 1990, pp. 48-50.

\& P. Raveschot, 'Veldstraat 55', Stadsarcheologie. Bodem en Monument in Gent, Gent, 14/4, 1990, pp. 98-99.

\& P. Raveschot, 'Waaistraat 1-3', Stadsarcheologie. Bodem en Monument in Gent, Gent, 14/3, 1990, pp. 53-57.

\& P. Raveschot, R. Van Nieuwenborgh, 'Eekhout 12', Stadsarcheologie. Bodem en Monument in Gent, Gent, 14/3, 1990, p. 51.

\& R. Van Nieuwenborgh, 'Gebroeders De Smetstraat', Stadsarcheologie. Bodem en Monument in Gent, Gent, 14/2, 1990, p. 51.

\section{1}

'Bijlokekaai', Stadsarcheologie. Bodem en Monument in Gent, Gent, 15/2, 1991, p. 32.

'Sint-Veerleplein 4', Stadsarcheologie. Bodem en Monument in Gent, Gent, 15/1, 1991, p. 63. 
\& J. De Block, 'Vrouwebroersstraat', Stadsarcheologie. Bodem en Monument in Gent, Gent, 15/2, 1991, pp. 35-37.

\& M. Helskens, 'Zwartezustersstraat', Stadsarcheologie. Bodem en Monument in Gent, Gent, 15/3, 1991, pp. 40-41.

\& P. Hoffsummer, P. Raveschot, 'Bijlokekaai, Ziekenzaal', Stadsarcheologie. Bodem en Monument in Gent, Gent, 15/1, 1991, pp. 56-57.

\& D. Lievois, 'Vrouwebroersstraat', Stadsarcheologie. Bodem en Monument in Gent, Gent, $15 / 3,1991$, p. 40 .

\& M. Meganck, P. Raveschot, 'Nieuwe Beestenmarkt-Slachthuisstraat', Stadsarcheologie. Bodem en Monument in Gent, Gent, 15/2, 1991, p. 34.

\& M. Meganck, P. Raveschot, 'Slachthuisstraat, Slachthuis', Stadsarcheologie. Bodem en Monument in Gent, Gent, 15/1, 1991, pp. 63-64.

\& P. Raveschot, 'Archeologisch onderzoek te Gent (O. Vl.)', in Archeologie 1990, Brussel, 1991, p. 66.

\& P. Raveschot, 'Bijlokekaai, Ziekenzaal', Stadsarcheologie. Bodem en Monument in Gent, Gent, 15/2, 1991, pp. 32-33.

\& P. Raveschot, 'Kantienberg', Stadsarcheologie. Bodem en Monument in Gent, Gent, 15/1, 1991, pp. 61-62.

\& P. Raveschot, 'Nieuwe Beestenmarkt-Slachthuisstraat', Stadsarcheologie. Bodem en Monument in Gent, Gent, 15/3, 1991, pp. 37-38.

\& P. Raveschot, 'Sint-Veerleplein, Gravensteen', Stadsarcheologie. Bodem en Monument in Gent, Gent, 15/2, 1991, pp. 35-37.

\& P. Raveschot, 'Stadsarcheologisch onderzoek in Gent (O. Vl.)', Archaeologia Mediaevalis, Brussel, 14, 1991, pp. 45-47.

\section{2}

(dir.), Tentoonstelling Wei en water, koe en pater. Ontwikkeling Heirnis-Macharius, Gent, 1992.

\& L. Bauters, P. Raveschot, 'Lange Steenstraat-Vrouwebroersstraat', Stadsarcheologie. Bodem en Monument in Gent, Gent, 16/3, 1992, p. 41.

\& J. De Meulemeester, 'Vingt années de recherches en archéologie médiévale', in Actes LIe Congrès de la Fédération des Cercles d'Archéologie et d'Histoire de la Belgique, Liège, 1, 1992 , p. 80.

\& G. Everaert, D. Lievois, 'Bijlokekaai, Ziekenhuis', Stadsarcheologie. Bodem en Monument in Gent, Gent, 16/4, 1992, pp. 56-57.

\& P. Raveschot, 'Sint-Machariusstraat-Spanjaardstraat', Stadsarcheologie. Bodem en Monument in Gent, Gent, 16/3, 1992, p. 43. 
\& P. Raveschot, H. Thoen, 'Sint-Veerleplein, Gravensteen', Stadsarcheologie. Bodem en Monument in Gent, Gent, 16/4, 1992, p. 58.

\section{3}

'Groentenmarkt 15', Stadsarcheologie. Bodem en Monument in Gent, Gent, 17/1, 1993, p. 34.

'Rabotstraat, Rabot', Stadsarcheologie. Bodem en Monument in Gent, Gent, 17/1, 1993, p. 35 .

'Sint-Pietersplein, Sint-Pietersabdij', Stadsarcheologie. Bodem en Monument in Gent, Gent, 17/2, 1993, pp. 53-55.

'Sint-Pietersplein, Sint-Pietersabdij', Stadsarcheologie. Bodem en Monument in Gent, Gent, 17/3, 1993, pp. 53-54.

'Stadsarcheologie: een onmiskenbare waarde voor de ontwikkeling van elke historische stad', in Rare jongens, die Vlamingen! Het archeologisch beleid in Vlaanderen, Leuven, 1993, p. 11.

'Vrijdagmarkt 9', Stadsarcheologie. Bodem en Monument in Gent, Gent, 17/3, 1993, pp. 56 57.

\& L. Bauters, P. Raveschot, 'Het klooster van de Geschoeide Karmelieten in Gent (O.Vl.)', Archaeologia Mediaevalis, Gent, 16, 1993, pp. 38-39.

\& D. Boncquet, G. Everaert, 'Lange Kruisstraat 4', Stadsarcheologie. Bodem en Monument in Gent, Gent, 17/1, 1993, p. 34.

\& D. Boncquet, G. Everaert, 'Sint-Baafsplein 36', Stadsarcheologie. Bodem en Monument in Gent, Gent, 17/1, 1993, p. 37.

\& G. Everaert, D. Lievois, G. Stoops, 'Goudenleeuwplein 1-2', Stadsarcheologie. Bodem en Monument in Gent, Gent, 17/3, 1993, pp. 46-50.

\& G. Everaert, D. Lievois, G. Stoops, ' Graslei 8', Stadsarcheologie. Bodem en Monument in Gent, Gent, 17/4, 1993, pp. 39-44.

\& D. Lievois, 'Lammerstraat, Marcellisbrug', Stadsarcheologie. Bodem en Monument in Gent, Gent, 17/3, 1993, p. 51.

\& P. Raveschot, 'Sint-Baafsabdij en Sint-Machariuswijk in Gent (O.Vl.)', Archaeologia Mediaevalis, Gent, 16, 1993, pp. 64-65.

\& P. Raveschot, 'Stadsarcheologisch onderzoek in Gent (O.Vl.)', Archaeologia Mediaevalis, Gent, 16, 1993, p. 63.

\& G. Stoops, 'Aan de voet van Jan-Frans Willems', De Geus van Gent, Gent, 25/6, 1993, pp. 8-9.

\& G. Stoops, 'Sint-Baafsplein', Stadsarcheologie. Bodem en Monument in Gent, Gent, 17/1, 1993, p. 35. 
\& G. Stoops, 'Limburgstraat 12', Stadsarcheologie. Bodem en Monument in Gent, Gent, 17/2, 1993, pp. 50-52.

\& G. Stoops, 'Rabotstraat, Rabot', Stadsarcheologie. Bodem en Monument in Gent, Gent, 17/3, 1993, pp. 51-53.

\& G. Stoops, 'Vlasmarkt 17', Stadsarcheologie. Bodem en Monument in Gent, Gent, 17/3, 1993, pp. 55-56.

\& G. Stoops, 'Sint-Baafsplein 32-34', Stadsarcheologie. Bodem en Monument in Gent, Gent, 17/4, 1993, pp. 46-47.

\section{4}

'Gandastraat 1, Sint-Baafsabdij', Stadsarcheologie. Bodem en Monument in Gent, Gent, 18/2, 1994, pp. 55-56.

'Het Sint-Baafsdorp, een archeologisch-historische kennismaking', Heemkundig Nieuws, Sint-Amandsberg, 22/4, 1994, pp. 2-3.

'De Sint-Pietersabdij in Gent (O.Vl.)', Archaeologia Mediaevalis, Brussel, 17, 1994, p. 32.

'Sint-Pietersplein, Sint-Pietersabdij', Stadsarcheologie. Bodem en Monument in Gent, Gent, 18/1, 1994, pp. 31-36.

'Wooncultuur in het middeleeuwse Gent', Heemkundig Nieuws, Sint-Amandsberg, 22/1, 1994, pp. 3-4.

\& L. Bauters, G. Stoops, 'Sint-Pietersplein, Sint-Pietersabdij', Stadsarcheologie. Bodem en Monument in Gent, Gent, 18/2, 1994, pp. 61-65.

\& G. Everaert, 'Bijlokekaai, Ziekenzaal', Stadsarcheologie. Bodem en Monument in Gent, Gent, 18/2, 1994, pp. 51-54.

\& G. Everaert, G. Stoops, 'Veldstraat 53', Stadsarcheologie. Bodem en Monument in Gent, Gent, 18/1, 1994, p. 37.

\& L. Fockedey, A. Lens, G. Stoops, 'Rabotstraat, Rabot', Stadsarcheologie. Bodem en Monument in Gent, Gent, 18/2, 1994, pp. 58-59.

\& G. Stoops, 'Gandastraat', Stadsarcheologie. Bodem en Monument in Gent, Gent, 18/2, 1994, pp. 54-55.

\& G. Stoops, 'Stadsarcheologisch onderzoek in Gent (O. Vl.)', Archaeologia Mediaevalis, Brussel, 17, 1994, pp. 59-61.

\section{5}

\& L. Bauters, A. Lens, G. Stoops,' Lange Steenstraat, Karmelietenkerk', Stadsarcheologie. Bodem en Monument in Gent, Gent, 19/1, 1995, pp. 49-52. 
\& D. Boncquet, 'Goudenleeuwplein 1-2', Stadsarcheologie. Bodem en Monument in Gent, Gent, 19/3, 1995, pp. 43-44.

\& L. Bauters, A. Lens, D. Lievois, G. Stoops, 'Het klooster van de Geschoeide Karmelieten in Gent (O.Vl.)', Archaeologia Mediaevalis, Namur 18/1, 1995, pp. 25-26.

\& A. Lens, D. Lievois, G. Stoops, 'Stadsarcheologisch onderzoek in Gent (O.Vl.)', Archaeologia Mediaevalis, Namur, 18/1, 1995, pp. 46-49.

\& G. Stoops, 'Drabstraat 12', Stadsarcheologie. Bodem en Monument in Gent, Gent, 19/1, 1995 , pp. 45-47.

\& G. Stoops, 'Langemunt/Onderstraat', Stadsarcheologie. Bodem en Monument in Gent, Gent, 19/1, 1995, p. 49.

\& G. Stoops, 'Lange Violettenstraat, Klein Begijnhof, Stadsarcheologie. Bodem en Monument in Gent, Gent, 19/1, 1995, pp. 52-54.

\& G. Stoops, 'Sint-Pietersplein, Sint-Pietersabdij', Stadsarcheologie. Bodem en Monument in Gent, Gent, 19/3, 1995, pp. 46-52.

\& G. Stoops, 'Vrouwebroersstraat, Karmelietenklooster', Stadsarcheologie. Bodem en Monument in Gent, Gent, 19/1, 1995, pp. 54-56.

\& G. Stoops, P. Swimberghe, 'Bijlokekaai, Hospitaalsite', Stadsarcheologie. Bodem en Monument in Gent, Gent, 19/3, 1995, pp. 40-42.

$\&$ H. Thoen, G. Stoops, 'Sint-Bernadettestraat 158-174', Stadsarcheologie. Bodem en Monument in Gent, Gent, 19/3, 1995, pp. 44-45.

\section{6}

'Archeologie in Gent. Een beknopte kennismaking', Nautilus Info, Gent, 20/7, 1996, pp. 5-9.

'Bijlokekaai', Stadsarcheologie. Bodem en Monument in Gent, Gent, 20/3, 1996, pp. 56-57.

'Goudenleeuwplein 3', Stadsarcheologie. Bodem en Monument in Gent, Gent, 20/4, 1996, pp. 44-45.

'Isabellakaai', Stadsarcheologie. Bodem en Monument in Gent, Gent, 20/3, 1996, pp. 60-61.

'Korenmarkt, Sint-Niklaaskerk', Stadsarcheologie. Bodem en Monument in Gent, Gent, 20/4, 1996, p. 46.

\& G. Everaert, 'Hoogpoort 58', Stadsarcheologie. Bodem en Monument in Gent, Gent, 20/4, 1996 , pp. 45-46.

E. Raeymaekers, G. Stoops, 'Ottogracht', Stadsarcheologie. Bodem en Monument in Gent, Gent, 20/3, 1996, pp. 61-63.

\& G. Stoops, 'Emile Braunplein', Stadsarcheologie. Bodem en Monument in Gent, Gent, 20/3, 1996, pp. 57-60. 
\& G. Stoops, 'Emile Braunplein', Stadsarcheologie. Bodem en Monument in Gent, Gent, 20/4, 1996, pp. 43-44.

\& G. Stoops, 'Sint-Veerleplein 11, Gravensteen', Stadsarcheologie. Bodem en Monument in Gent, Gent, 20/4, 1996, pp. 46-49.

\& G. Stoops, 'Werregarenstraat', Stadsarcheologie. Bodem en Monument in Gent, Gent, 20/3, 1996, p. 64 .

\section{7}

'In Memoriam Maurits Gysseling', Stadsarcheologie. Bodem en Monument in Gent, Gent, 21/3-4, 1997, p. 6.

'Korenmarkt, Sint-Niklaaskerk', Stadsarcheologie. Bodem en Monument in Gent, Gent, 21/1, 1997, pp. 26-27.

'Korenmarkt, Sint-Niklaaskerk', Stadsarcheologie. Bodem en Monument in Gent, Gent, 21/2,1997, p. 29.

'Mahatma Gandhistraat 30', Stadsarcheologie. Bodem en Monument in Gent, Gent, 21/3-4, 1997, pp. 100-102.

Wasstraat, Stadsarcheologie. Bodem en Monument in Gent, Gent, 21/3-4, 1997, p. 104.

\& L. Bauters, G. Stoops, 'Vrouwebroersstraat, Karmelietenklooster', Stadsarcheologie. Bodem en Monument in Gent, Gent, 21/1, 1997, pp. 31-34.

\& J. Bourgeois, G. Stoops, 'Kouter', Stadsarcheologie. Bodem en Monument in Gent, Gent, 21/3-4, 1997, pp. 98-100.

\& S. Derom, G. Everaert, 'Gandastraat, Sint-Baafsabdij', Stadsarcheologie. Bodem en Monument in Gent, Gent, 21/3-4, 1997, pp. 96-97.

\& G. Everaert, 'Bijlokekaai, Hospitaal', Stadsarcheologie. Bodem en Monument in Gent, Gent, 21/3-4, 1997, pp. 92-94.

\& E. Raeymaekers, 'Bibliotheekstraat', Stadsarcheologie. Bodem en Monument in Gent, Gent, 21/3-4, 1997, pp. 91-92.

\& E. Raeymaekers, 'Vrijdagmarkt 40', Stadsarcheologie. Bodem en Monument in Gent, Gent, 21/3-4, 1997, p. 104.

\& G. Stoops, 'Emile Braunplein', Stadsarcheologie. Bodem en Monument in Gent, Gent, 21/2, 1997, pp. 23-24.

\& G. Stoops, 'Goudenleeuwplein', Stadsarcheologie. Bodem en Monument in Gent, Gent, 21/2, 1997, pp. 24-28.

\& G. Stoops, 'Graslei', Stadsarcheologie. Bodem en Monument in Gent, Gent, 21/2, 1997, pp. 28-29. 
\& G. Stoops, 'Onderbergen 2, Hof van Ravenstein', Stadsarcheologie. Bodem en Monument in Gent, Gent, 21/1, 1997, pp. 28-29.

\& G. Stoops, 'Prooststraat, Brouwerij Sint-Baafsabdij', Stadsarcheologie. Bodem en Monument in Gent, Gent, 21/1, 1997, pp. 29-31.

\& G. Stoops, 'Werregarenstraat', Stadsarcheologie. Bodem en Monument in Gent, Gent, 21/1, 1997, p. 34.

\& G. Stoops, H. Thoen, 'Botermarkt', Stadsarcheologie. Bodem en Monument in Gent, Gent, 21/3-4, 1997, pp. 94-96.

\& G. Stoops, G. Vermeiren, 'Jakobijnenstraat', Stadsarcheologie. Bodem en Monument in Gent, Gent, 21/3-4, 1997, pp. 97-98.

\& G. Stoops, G. Vermeiren, 'Posteernestraat 21', Stadsarcheologie. Bodem en Monument in Gent, Gent, 21/3-4, 1997, pp. 102-103.

\& H. Thoen, 'In Memoriam René De Vos', Stadsarcheologie. Bodem en Monument in Gent, Gent, 21/3-4, 1997, p. 4.

\section{8}

'Drabstraat 41', Stadsarcheologie. Bodem en Monument in Gent, Gent, 22/2, 1998, pp. 51 53.

'Gandastraat, Sint-Baafsabdij', Stadsarcheologie. Bodem en Monument in Gent, Gent, 22/2, 1998 , pp. 53-57.

'Gustaaf Callierlaan', Stadsarcheologie. Bodem en Monument in Gent, Gent, 22/4, 1998, p. 48.

\& L. Bauters, G. Stoops, 'Maaseikstraat, Sint-Baafskathedraal', Stadsarcheologie. Bodem en Monument in Gent, Gent, 22/4, 1998, pp. 49-51.

\& M. Beyaert, G. Stoops, 'Grootkanonplein, Groot Kanon', Stadsarcheologie. Bodem en Monument in Gent, Gent, 22/2, 1998, pp. 57-60.

$\&$ N. Barbry, L. Charles, G. Everaert, D. Lievois, 'Gouvernementstraat 20', Stadsarcheologie. Bodem en Monument in Gent, Gent, 22/4, 1998, pp. 46-48.

\& S. Derom, E. Raeymaekers, 'Vrijdagmarkt 66-69', Stadsarcheologie. Bodem en Monument in Gent, Gent, 22/3, 1998, pp. 40-41.

\& G. Deseyn, G. Stoops, 'Sint-Pietersnieuwstraat 99-101', Stadsarheologie. Bodem en Monument in Gent, Gent, 22/4, 1998, pp. 51-54.

\& D. Lievois, 'Veldstraat 80', Stadsarcheologie. Bodem en Monument in Gent, Gent, 22/4, 1998, p. 56.

\& E. Raeymaekers, 'Limburgstraat', Stadsarcheologie. Bodem en Monument in Gent, Gent, 22/1, 1998, pp. 35-37. 
\& E. Raeymaekers, 'Limburgstraat', Stadsarcheologie. Bodem en Monument in Gent, Gent, 22/3, 1998, pp. 38-40.

\& E. Raeymaekers, 'Volmolenstraat', Stadsarcheologie. Bodem en Monument in Gent, Gent, 22/3, 1998, p. 40.

\& E. Raeymaekers, G. Stoops, 'Korenmarkt, Sint-Niklaaskerk', Stadsarcheologie. Bodem en Monument in Gent, Gent, 22/3, 1998, p. 35.

\& E. Raeymaekers, G. Stoops, G. Vermeiren, 'Korenmarkt, Sint-Niklaaskerk', Stadsarcheologie. Bodem en Monument in Gent, Gent, 22/2, 1998, pp. 61-71.

\& G. Stoops, 'Gandastraat, Sint-Baafsabdij', Stadsarcheologie. Bodem en Monument in Gent, Gent, 22/3, 1998, pp. 32-35.

\& G. Stoops, 'Korenmarkt', Stadsarcheologie. Bodem en Monument in Gent, Gent, 22/1, 1998, pp. 31-33.

\& G. Stoops, 'Korenmarkt', Stadsarcheologie. Bodem en Monument in Gent, Gent, 22/2, 1998 , p. 60.

\& G. Stoops, 'Sint-Pietersplein, Sint-Pietersabdij', Stadsarcheologie. Bodem en Monument in Gent, Gent, 22/2, 1998, pp. 74-75.

\section{9}

\& N. Barbry, L. Charles, G. Everaert, E. Raeymaekers, G. Stoops, 'Goudenleeuwplein 3', Stadsarcheologie. Bodem en Monument in Gent, Gent, 23/1, 1999, pp. 79-81.

\& L. Bauters, G. Stoops, G. Vermeiren, 'Abdijen, kerken en kloosters in Gent (O.-Vl.)', Archaeologia Mediaevalis, Gent, 22, 1999, pp. 42-43.

\& M. Beyaert, G. Everaert, D. Lievois, G. Stoops, 'Grootkanonplein, Groot Kanon', Stadsarcheologie. Bodem en Monument in Gent, Gent, 23/1, 1999, pp. 81-83.

\& E. Raeymaekers, 'Mahatma Gandhistraat 30, Hoosmolen', Stadsarcheologie. Bodem en Monument in Gent, Gent, 23/1, 1999, p. 85.

\& G. Stoops, 'Stadsarcheologisch onderzoek in Gent (O.-Vl.)', Archaeologia Mediaevalis, Gent, 22, 1999, pp. 68-70.

\& H. Vandenborre, 'Gandastraat, Sint-Baafsabdij', Stadsarcheologie. Bodem en Monument in Gent, Gent, 23/1, 1999, p. 79.

\section{0}

'Sas- \& Bassijnwijk: het Rijke Klarenklooster', in Gentse stadsgezichten, Gent, 2000, pp. 3637.

Sint-Amandsberg: de negenmeimarkt', in Gentse stadsgezichten, Gent, 2000, pp. 56-57.

'Wondelgem: de Vroonstalledries', in Gentse stadsgezichten, Gent, 2000, pp. 40-41. 
\& J. Bastiaens, 'Ledeberg: de ajuinmarkt', in Gentse stadsgezichten, Gent, 2000, pp. 52-53.

$\&$ K. De Groote, e.a., 'Het verleden van de Gentse Korenmarkt', Archaeologia Mediaevalis, Brussel, 23, 2000, p. 67.

\& A. Ervynck, G. Stoops, 'De Korte Ridderstraat, een verdwenen stadsgezicht', in Gentse stadsgezichten, Gent, 2000, pp. 4-5.

\& G. Stoops, 'Stadsarcheologisch onderzoek in Gent (O.-Vl.)', Archaeologia Mediaevalis, Brussel, 23, 2000, pp. 67-70.

$\&$ F. Vermeulen, 'Sint-Denijs-Westrem: archeologische site - vliegveld-Flanders Expo', in Gentse stadsgezichten, Gent, 2000, pp. 48-49.

\section{1}

\& D. Lievois, A. Rambaut, 'De Heilig-Kruiskerk', in Open Monumentendag, Gent, 2001, p. 29.

\section{2}

'Hospitalen en ziekenzorg in Gent. Een bijdrage van de stadsarcheologie', Archaeologia Mediaevalis 25. Pré-actes/introductie-teksten, Namur, 2002, p. 10.

$\&$ D. Lievois, 'Kapel Onze-Lieve-Vrouw van Troost, Sint-Kruis-Winkel', in Open Monumentendag 2002, Gent, 2002, p. 31.

\& D. Lievois, 'Rostijne', in Open Monumentendag 2002, Gent, 2002, p. 30.

\& A Rambaut, G. Stoops, G. Vermeiren, 'Archeologisch onderzoek in Sint-Kruis-Winkel (Gent) (O. Vl.)', Archaeologia Mediaevalis, Gent-Brussel/Bruxelles-Namur, 25, 2002, pp. 25-26.

\& G. Stoops, G. Vermeiren, 'Archeologisch onderzoek in Gent (O. Vl.)', Archaeologia Mediaevalis, Gent-Brussel/Bruxelles-Namur, 25, 2002, pp. 62-65.

\section{5}

\& M.A. Bru, J. Huyghe, K. Rutten, G. Vermeiren, 'Archeologisch onderzoek op het SintPietersplein in Gent (O.-Vl.)', Archaeologia Mediaevalis, Namur, 28, 2005, pp. 80-81.

\& M.A. Bru, P. Steurbaut, G. Stoops, G. Vermeiren, 'Archeologisch onderzoek in Gent (O.-Vl.)', Archaeologia Mediaevalis, Namur, 28, 2005, pp. 78-80.

\& M.A. Bru, G. Stoops, Archeologisch onderzoek op de Bijlokesite in Gent (O.-Vl.), Archaeologia Mediaevalis, Namur, 28, 2005, pp. 81-82.

\& M.A. Bru, G. Vermeiren, 'Archeologisch en bouwhistorisch onderzoek naar de verdwenen Sint-Veerlekerk in Gent (O.-Vl.)', Archaeologia Mediaevalis, Namur, 28, 2005, pp. 89-91. 


\section{6}

\& G. Antheunis, M.A. Bru, E. Raeymaekers, P. Steurbaut, G. Stoops, G. Vermeiren, 'Archeologisch onderzoek in Gent (O.-Vl.)', Archaeologia Mediaevalis, Gent, 29, 2006, pp. 2-3.

\section{7}

\& B. Acke, G. Antheunis, M.A. Bru, P. Steurbaut, G. Stoops, R. Trommelmans, G. Vermeiren, 'Archeologisch onderzoek in Gent (O.-Vl.)', Archaeologia Mediaevalis, Brussel, 30, 2007, pp. 2-5.

\& G. Everaert, G. Stoops, 'Hoogpoort 17', in Archeologisch onderzoek in Gent 1999-2006, (Stadsarcheologie. Bodem en Monument in Gent, 2/1), Gent, 2007, pp. 41-46.

\section{8}

'Slachthuisstraat', in Archeologisch onderzoek in Gent, 1997-2008, (Stadsarcheologie. Bodem en Monument in Gent, 2/2), Gent, 2008, pp. 157-160.

\& G. Antheunis, M.A. Bru, G. Stoops, G. Vermeiren, 'Archeologisch onderzoek in Gent (O.-Vl.)', Archaeologia Mediaevalis, Gent, 31, 2008, pp. 8-10.

\& L. Charles, D. Lievois, P. Steurbaut, 'Raveschootstraat, Hof van Raveschoot', in Archeologisch onderzoek in Gent, 1997-2008, (Stadsarcheologie. Bodem en Monument in Gent, 2/2), Gent, 2008, p. 76.

\& D. Laporte, G. Stoops, 'Prinsenhof 105', in Archeologisch onderzoek in Gent, 1997-2008, (Stadsarcheologie. Bodem en Monument in Gent, 2/2), Gent, 2008, pp. 71-73.

\& G. Rabau, E. Raeymaekers, 'Burgstraat 46, Klooster van de geschoeide karmelieten', in Archeologisch onderzoek in Gent, 1997-2008, (Stadsarcheologie. Bodem en Monument in Gent, 2/2), Gent, 2008, pp. 14-17.

\& E. Raeymaekers, 'Wasstraat', in Archeologisch onderzoek in Gent, 1997-2008, (Stadsarcheologie. Bodem en Monument in Gent, 2/2), Gent, 2008, p. 161.

\& G. Stoops, 'Sint-Pietersplein 9-14, Sint-Pietersabdij', in Archeologisch onderzoek in Gent, 1997-2008, (Stadsarcheologie. Bodem en Monument in Gent, 2/2), Gent, 2008, pp. 9499.

\section{9}

\& M. Berkers, M.A. Bru, P. Steurbaut, G. Stoops, G. Vermeiren, 'Archeologisch onderzoek in Gent (O.-Vl.)', Archaeologia Mediaevalis, Gent, 32, 2009, pp. 84-87.

\& P. Steurbaut, 'Walsites in Gent (O.-Vl.)', Archaeologia Mediaevalis, Gent, 32, 2009, pp. 141-142. 


\section{0}

\& M. Berkers, P. Steurbaut, G. Stoops, 'Archeologisch onderzoek in Gent (O.-Vl.)', Archaeologia Mediaevalis, Brussel, 33, 2010, pp. 22-25.

\section{1}

\& M. Berkers, M.A. Bru, P. Steurbaut, G. Stoops, G. Vermeiren, 'Archeologisch onderzoek in Gent in 2010 (O.-Vl.)', Archaeologia Mediaevalis, Namur, 34, 2011, pp. 12-17.

\section{2}

\& G. Vermeiren, M.A. Bru, 'Botermarkt-Belfortstraat in Gent (O.-Vl.)', Archaeologia Mediaevalis, Gent, 35, 2012, pp. 242-243.

\section{3}

'De Raad van Vlaanderen in steen', @rchieflink, Gent, 15/1, 2015, p. 7.

'Ter herinnering aan Prudens', @rchieflink, Gent, 13/3, 2013, p. 7.

\& M. Berkers, M.A. Bru, G. Stappers, Steurbaut, G. Stoops, G. Vermeiren, 'Archeologisch onderzoek in Gent (O.-Vl.)', Archaeologia Mediaevalis, Brussel, 36, 2013, pp. 18-19.

\section{5}

Gent. Laatmiddeleeuwse draken, (Erfgoedmemo, 80), Gent, 2015.

\& G. Vermeiren, 'Information to die for! 40 jaar stadsarcheologie Gent. Wat weten we over dood en begrafenis', in Ten Duinen 7th international colloquium Doden spreken Dead man talking, Koksijde, 2015, p. 56. 


\title{
Laudatio voor Marie Christine Laleman
}

\author{
Leo Pée
}

Beste Marie Christine,

Het heeft mij veel tijd, veel zweet en gelukkig geen tranen gekost om inzicht te krijgen in uw reilen en reilen, in uw professionele activiteiten en vooral in uw ongelooflijk vele wetenschappelijke bijdragen.

Op 27 april 2017 werd Marie Christine Laleman, directeur van De Zwarte Doos en Stadsarcheologie Gent, naar aanleiding van haar nakend pensioen uitgewuifd. Bij die gelegenheid hielden Dirk Callebaut en Jean Bourgeois de feestredes en werd door schepen Annelies Storms aan Marie Christine een feestbundel overhandigd zeg maar een soort "Liber Amicorum" -, waarvoor Stadsarcheologie Gent en het Departement Cultuur, Sport en Vrije Tijd hun krachten hadden gebundeld. De tientallen bevriende vorsers die speciaal hiervoor artikels pleegden vormen een brede waaier aan auteurs, archeologen, historici, kunsthistorici, ja zelfs natuurwetenschappers, die elk vanuit hun vakgebied bijgedragen hebben; resultaat: een publicatie die van een multidisciplinaire insteek getuigt. De redactie was in handen van Dr. Koen De Groote en Dr. Anton Ervynck, beiden werkzaam bij het agentschap Onroerend Erfgoed, maar met een lange en zeer gewaardeerde band met de Gentse stadsarcheologie.

Deze feestbundel draagt als titel: "Gentse Geschiedenissen ofte Nieuwe Historiën uit de oudheid der stad en illustere plaatsen omtrent Gent". Hierin zijn, op basis van archeologisch en historisch onderzoek, nieuwe theorieën, maar ook niet eerder gepubliceerde onderwerpen over het Gentse verleden samengebundeld. Deze "Geschiedenissen" zijn een opeenvolging van bijdragen die het chronologisch verhaal van de stad toelichten, maar behandelen tevens onderwerpen die nauw aansluiten bij de Gentse voorbeelden. Een ruimere geografische context staat binnen dit boek dan ook garant voor toetsing, vergelijking en aanvulling over de stadsgrenzen heen en dit alles - zoals gezegd - geïnspireerd door een multidisciplinaire aanpak.

Kortom: een feilloze weerspiegeling van de carrière en het ongewoon omvangrijk wetenschappelijk oeuvre van Marie Christine Laleman, waarin "de oudheid der stad en illustere plaatsen omtrent Gent" altijd centraal heeft gestaan. 
Met andere woorden: Marie Christine Laleman voldoet als geen ander aan de voorwaarden en doelstellingen van de tweejaarlijkse Frans De Potter - Jan Broeckaertprijs, namelijk "... het bevorderen van de kennis van de plaatselijke, gewestelijke en provinciale geschiedenis van Oost-Vlaanderen". Deze prijs houdt in: "Het bekronen van het gezamenlijk oeuvre van een lokale historicus, die het verleden van zijn dorp of streek op een wetenschappelijke en originele wijze heeft beschreven". Uiteraard kan dat ook een stad met haar illustere omliggende plaatsen zijn.

Vandaar dat de negen kringen van het Oost-Vlaams Verbond van de Kringen voor Geschiedenis unaniem Marie Christine hebben voorgedragen voor deze Frans De Potter - Jan Broeckaertprijs. Zodoende wordt zij dus vandaag opgenomen in de illustere kring van laureaten.

Intussen zijn - sinds 1983 - haar dienaangaande al 18 eminente plaatselijke historici voorafgegaan. Tot 1999 was dat telkens tijdens één van de tweejaarlijkse colloquia van genoemd Oost-Vlaams Verbond. Weliswaar werden deze colloquia na 1999 opgegeven, enerzijds wegens de te kleine opkomst van geïnteresseerde deelnemers en anderzijds omdat de organisatie van zo'n evenement te zwaar rustte op de schouders van slechts enkelen. Doch de Frans De Potter - Jan Broeckaertprijs werd met klem behouden. Sindsdien werd hij steeds uitgereikt tijdens de Algemene Vergadering van het Verbond; vergadering die werd uitgebreid tot een volle dag, door toevoeging van namiddagactiviteiten, meestal onder de vorm van een bezoek aan het cultuur-historisch patrimonium van de steeds wisselende plaats, de jaarvergadering doorging.

Achtereenvolgens passeerden het revue: Jozef De Brouwer (1983), Jozef De Wilde (1985), Marcel Bovyn (1987), Achiel De Vos (1989), Paul Van Butsele (1991), Jef Scheerders (1993), Herman Maes (1995), Geert Van Bockstaele (1997), Luc Stockman (1999), Luc Van Durme (2002), ikzelf (2003), Ric Castelain (2005), Hilaire Liebaut (2007), Hugo Notteboom (2009), Danny Lamarcq (2011), Daniël Lievois (2013), Dirk Van de Perre (2015) en Aimé Stroobants (2017).

Vandaag is het dus de beurt aan Marie Christine Laleman.

Als een rode draad loopt doorheen haar leven en haar carrière de stad Gent en omliggende plaatsen. Al was zij ook elders actief, zelfs in het buitenland, tot in Rome toe.

Zij werd te Gent geboren - ik ga niet meedelen wanneer, want dat is onbeleefd maar het was in de mooie bloemenmaand mei. $\mathrm{Zij}$ liep vlotjes door het lager, middelbaar (Grieks-Latijnse humaniora) en hoger onderwijs. Aan de Gentse Rijksuniversiteit promoveerde zij in juni 1973 tot licentiaat Kunstgeschiedenis en Oud- 
heidkunde, met grootste onderscheiding en met als proefschrift: Archeologische studie over het gebouwencomplex van de abdij Vauclair; haar promotor was Prof. Dr. Firmin De Smidt.

En vervolgens speelden haar professionele loopbaan en haar wetenschappelijk werk zich af in Gent en hoofdzakelijk over Gent.

Reeds tijdens haar studies en enkele daaropvolgende jaren deed zij archeologische stages in Frankrijk, namelijk in Vauclair, Vorges en Laon.

Maar de serieuze beroepsactiviteiten gingen van start in 1973 in de Sint-Pietersabdij, waar sinds datzelfde jaar opgravingen plaats hadden in de oostelijke buitentuin van de abdij, en waar nadien dan ook het centrum werd gevestigd van de Gentse stadsarcheologie. Jaren later werd deze dienst overgebracht naar het Hof van Ryhove in de Onderstraat.

Vanaf 1973 was Marie Christine Laleman verbonden aan de Dienst Culturele Zaken van de Stad Gent, eerst als wetenschappelijk medewerker tot eind 1976, vervolgens als wetenschappelijk assistente (tot 1992). Intussen, in 1985, legde zij met succes het examen af van Conservator Dienst Monumentenzorg en Stadsarcheologie. Nadien promoveerde zij achtereenvolgens tot Conservator Dienst Stadsarcheologie (1993), tot Stadsarcheoloog (1995), tot Adviseur Stadsarcheologie (1999) en tot Directeur in 2011.

Middelerwijl, in 2005, werd zij met al haar collega's en met de hele archeologische inboedel opgeborgen in die grote "De Zwarte Doos" aan de Dulle-Grietlaan in Gentbrugge, in de gerestaureerde gebouwen van de vroegere Puntfabriek (het metaalbedrijf Arbed), waar toen tevens het Gentse Stadsarchief werd ondergebracht. Daar werd Marie Christine in 2011 tot directeur benoemd van de Dienst Stadsarcheologie en Stadsarchief; sinds 2015 heette zij Directeur Stadsarchief Gent \& Stadsarcheologie Gent en op 1 januari 2017 werd het Directeur Zwarte Doos \& Stadsarcheologie Gent, ... tot zij dus op 1 juni 2017 met pensioen ging.

In het verlengde van haar professionele opdracht, maar ook uit zuiver persoonlijke interesse was zij tevens actief bij diverse verenigingen, organisaties en evenementen. Ziehier een korte opsomming:

- 1973-1975: lid van de wetenschappelijke werkgroep voor de tentoonstelling "Gent, duizend jaar kunst en cultuur";

- 1977-2001: stichtend lid en lid van de Raad van Bestuur van de vzw Gentse Vereniging voor Stadsarcheologie, eveneens hoofdredacteur van het tijdschrift Stadsarcheologie. Bodem en monument in Gent; 
- 1978-2009: Stichtend lid en medeorganisator van de jaarlijkse nationale contactdagen voor middeleeuwse archeologie Archaeologia Mediaevalis; vanaf 1982 ook verantwoordelijk voor de sectie Stadsarcheologie en vanaf 1991 hoofdverantwoordelijke voor Vlaanderen;

- 1978-1980: lid van de wetenschappelijke werkgroep voor de tentoonstelling Benedictus in de Nederlanden;

- 1980-1985: medewerker aan het Nationaal Biografisch Woordenboek;

- 1981-2001: stichtend lid en lid van de Raad van Bestuur van de Vereniging voor Industriële Archeologie en Textiel, Gent;

- 1982: Stichtend lid en lid van de Raad van Bestuur van de Vereniging voor Interdisciplinair Archeologisch-Natuurwetenschappelijk Onderzoek;

- vanaf 1991: bestuurslid (en sinds 2008 ondervoorzitter) van de Gentse Maatschappij voor Geschiedenis en Oudheidkunde

- 1991-2004: lid van de Koninklijke Commissie voor Monumenten en Landschappen, afdeling provincie Oost-Vlaanderen;

- 1995-2001: lid van de Vlaamse Archeologische Raad;

- 1995-1996: lid van de werkgroep 'Overheid en opdrachten’ Vlaams centrum voor Ambacht en Restauratie voor de Koning Boudewijnstichting;

- 1997-2014: bestuurslid namens de Stad Gent in de vzw Museum voor Volkskunde, later omgevormd tot vzw Huis van Alijn;

- 2000-2014: bestuurslid namens de stad Gent van de vzw Gent Cultuurstad;

- 2003-2009: werkend lid van de vzw Bouwhistorie;

- vanaf 2003: geassocieerd lid van het Einhard-Instituut. Onderzoeksinstituut voor Middeleeuwse Studies van de Gentse universiteit, later PirenneInstituut;

- 2004-2014: lid van de Koninklijke Commissie voor Monumenten en Landschappen, afdeling 3: archeologie;

- 2006-2014: secretaris van de vzw Gent Cultuurstad;

- 2009: stichtend lid van de vzw ASBL - Archaeologia Mediaevalis.

En verder fungeerde zij als jurylid bij talrijke provinciale en stedelijke prijzen of in allerhande examencommissies, zowel in Oost-als West-Vlaanderen; evenzo was zij gedurende jaren ook regelmatig gastdocente aan het Instituut voor Restauratie en Conservatie, Postgraduaat Monumentenzorg (1986-1991), aan de postgraduale opleiding monumentenzorg in het Henry Van de Velde-instituut te Antwerpen en aan de opleiding Middeleeuwse archeologie en Stadsarcheologie in de Gentse universiteit. 
Haar professionele activiteiten werden in hoofdzaak bepaald door het stadsarcheologisch onderzoek in Gent. Zo werkte zij in de jaren 70 van de vorige eeuw in Gent mee aan de uitbouw van de eerste stadsarcheologische dienst van België en vanaf 1977 werd ze belast met de leiding en de coördinatie van de afdeling Stadsarcheologie binnen de Dienst Monumentenzorg en Stadsarcheologie; de verdere opgang van haar carrière hebben wij hierboven reeds uitvoerig meegedeeld.

Opvallend in haar activiteiten is haar grote veelzijdigheid:

- doelgericht en gecoördineerd archeologisch onderzoek;

- opgravingen, muurwerkarcheologie en prospecties;

- wetenschappelijk verwerking, zowel van de verrichte als van vroegere opgravingen;

- educatief werk, nl. leiding en medewerking aan tentoonstellingen, infostands, diamontages, voordrachten, rondleidingen, brochures, enz.;

- bijdragen tot allerlei initiatieven ter bevordering van inter- en multidisciplinaire samenwerkingsverbanden:

- coördinerende en organiserende taken binnen verscheidene werkgroepen;

- medewerking aan projecten ter bevordering van bouwhistorisch onderzoek en kwaliteitsvolle herwaardering van archeologisch en bouwkundig erfgoed;

- lezingen, referaten, cursussen en opleidingen in het kader van congressen, werkseminaries en gespecialiseerde werkgroepen;

- beheerondersteunende, adviserende en administratieve taken op gemeentelijk niveau;

- management archiefinstellingen en onroerende erfgoed binnen de stad Gent

Het wetenschappelijke oeuvre dat Marie Christine Laleman in de loop van al die jaren heeft verwezenlijkt is ronduit buitengewoon omvangrijk. In de bibliografie die Anne-Laure Van Brouane ons ter beschikking heeft gesteld, telden wij zo maar eventjes 323 bijdragen van respectabele of minder grote omvang en 290 kortere artikels. En dan zijn haar prestaties van de laatste twee jaar nog niet eens meegerekend. Nu eens waren het bijdragen van haar hand, dan weer artikels, waarbij zij als coauteur optrad; waaruit trouwens meteen haar groot vermogen blijkt om samen met anderen in een ideaal teamverband actief te zijn. Haar belangrijkste wetenschappelijke compagnons de route, waren - in volgorde van belangrijkheid - Patrick Raveschot (133), Gunter Stoops (74), Daniël Lievois (54), Guido Everaert (29), Leen Charles (22) en Geert Vermeiren (20).

En haar wetenschappelijk werk vond vrij vlug de weg naar het buitenland. Publicaties van haar hand - al dan niet met coauteurs - kwamen van de persen in Neder- 
land (Amsterdam, Rotterdam, 's Gravenhage, Apeldoorn, Nijmegen, Zutphen en Zwolle), in Luxemburg (Luxembourg-stad), in Frankrijk (Parijs, Nancy en Caen), in Groot-Brittannië (Chester) en zelfs in Italië (Rome).

Het is uiteraard een onbegonnen opgave om in dit korte tijdsbestek een overzicht te geven van alle boeken, tijdschriften of brochures, waarvoor zij bijdragen heeft geleverd; hiervoor verwijs ik naar de minutieus opgemaakte bibliografie van AnneLaure.

Toch wil ik enkele in het oog springende periodieken vermelden:

- het tijdschrift Stadsarcheologie Gent (1977-1993), waarin 162 artikels;

- het tijdschrift Stadsarcheologie. Bodem en monument in Gent, dat mede door haarzelf werd gesticht en waarvan zij jarenlang hoofdredacteur is geweest, met 111 artikels

- het tijdschrift Archaeologia Mediaevalis, met 53 notities;

- de Handelingen der Maatschappij voor Geschiedenis en Oudheidkunde, waarin zij mede verantwoordelijk was voor de rubriek Bibliografie van de geschiedenis van Gent en waarvoor zij diverse eminente bijdragen heeft geleverd; zoals reeds gezegd, neemt zij sinds 2008 in genoemde maatschappij de functie van ondervoorzitter waar.

Haar hele oeuvre wordt hoofdzakelijk beheerst door volgende thema's:

- stadsarcheologisch onderzoek, in Gent, in België en in het algemeen;

- resultaten en bevindingen van archeologische onderzoeksprojecten in Gent;

- synthesebijdragen rond archeologisch-historische vraagstukken over Gent;

- coördinatie van inter- en multidisciplinaire uitwerking van onderzoeksprojecten in Gent;

- coördinatie, synthese en detailonderzoeken over de huizen in Gent. In dit verband is het werk dat zij samen met Patrick Raveschot schreef, vermeldenswaardig, namelijk Inleiding tot de studie van de woonhuizen in Gent, periode 1100-1300: de kelders, waarvoor zij tot laureate werd bekroond door de Koninklijke Academie voor Wetenschappen, Letteren en Schone Kunsten van België. Dit was meteen de aanleiding tot een reeks artikels, in samenwerking met Patrick Raveschot en Daniël Lievois, getiteld De geschiedenis achter de façade, waarin bouwhistorisch onderzoek van heel wat Gentse huizen. Haar studie over de middeleeuwse stenen (waarmee stenen huizen worden bedoeld) wordt nog steeds geactualiseerd en bijgehouden door de collega's van Stadsarcheologie Gent. 
- en verdere thema's, zoals bouwkundige onderwerpen en architecten; opmerkelijk in dit verband is haar studie - in samenwerking met de huidige directeur Geert Vermeiren -, getiteld Ruimte en bewoning in het centrum van het middeleeuwse Gent, in de Handelingen van de Gentse Maatschappij voor Geschiedenis en Oudheidkunde, in 2010.

- voorts ook interdisciplinaire aspecten van archeologie en bouwgeschiedenis;

- cultureel erfgoed en patrimoniumzorg in Gent en in het algemeen;

- resultaten en bevindingen in verband met de ontwikkeling van het bouwvak, de bouwtechniek en de bouwmaterialen doorheen de tijden.

Marie Christine is ook inspiratiebron en luisterend oor geweest voor een nieuwe generatie archeologen en historici.

En wie dacht dat zij bij haar rustpensioen ook daadwerkelijk op rust is gegaan, heeft het mis. Zij blijft onverwijld deel uitmaken van het bestuur van de Gentse Maatschappij voor Geschiedenis en Oudheidkunde en van de adviesraad van de Duinenabdij in Koksijde. Zij blijft geïnteresseerd aanwezig bij de activiteiten in het Gentse Museum van Schone Kunsten, in het Archief en bij de Stadsarcheologie Gent.

En eveneens blijft zij onvermoeid doorgaan met het realiseren van wetenschappelijke publicaties, ten bewijze haar studie over de buurt van de Krook in het Krookboek, haar studie in de Handelingen van de Gentse Maatschappij over de domeinen van de Cisterciënzers in de buurt van Sint-Kruis-Winkel en haar studie over het Spaans Kasteel. Benieuwd wat zij ons dit nieuwe jaar nog zal bieden.

Maar één ding is zeker: Gent, het Middeleeuws Manhattan, zal haar ongetwijfeld nog jarenlang blijven boeien!

Beste Marie Christine, mag ik u vragen deze herinneringsoorkonde en de prijs in ontvangst te willen nemen. Misschien lijkt deze prijs, in vergelijking met andere provinciale prijzen, slechts een nederige erkenning voor uw vele verdiensten; doch hij wordt u gejond vanuit een algemeen gevoel van waardering vanwege het Oost-Vlaams Verbond en de negen kringen die er deel van uitmaken. En dat maakt deze prijs voor u ongetwijfeld tot een waardevolle en unieke bekroning van het historisch en archeologisch navorsingswerk dat $\mathrm{u}$ tot nu toe reeds verwezenlijkte en laten wij hopen - ook tot een extra stimulans voor verder onderzoek.

Ronse, 26 januari 2019. 


\title{
Dankwoord
}

\author{
Marie Christine Laleman
}

\section{Naar aanleiding van het toekennen van de Prijs Frans De Potter en Jan Broeckaert in Ronse op 26 januari 2019}

Beste allen,

De toekenning van de prijs Frans De Potter en Jan Broeckaert 2019 stemt me uiteraard gelukkig. En graag wil ik daarvoor jullie, het Oost-Vlaams Verbond van de Kringen voor Geschiedenis, alle aangesloten verenigingen en de subsidiërende overheid, de provincie Oost-Vlaanderen, danken voor deze erkenning ter bevordering van lokale geschiedenis. En bewust, of niet, door mij als laureaat te bekronen, heeft het Verbond voor een meervoudige vernieuwing gezorgd.

Uiteraard vervoeg ik daardoor een rij van illustere Oost-Vlaamse onderzoekers die in de spirit van Frans De Potter (1824-1904) en Jan Broeckaert (1837-1911) uit bronnen gedistilleerde kennis ter beschikking stellen van anderen. De eerste die deze rij aanvoert, Jozef De Brouwer, werd in 1983 bekroond. En om de twee jaar wordt daar een nieuwe laureaat aan toegevoegd. $\mathrm{Nu}$ in 2019 is dit voor het eerst een vrouw en hoewel ik zeker geen harde feministe ben, toch wil ik de bekroning onrechtstreeks interpreteren als een erkenning voor wat talrijke vrouwelijke onderzoekers in Oost-Vlaanderen, al dan niet in het kader van hun beroepsactiviteiten, realiseren.

Voor het eerst ook wordt de Prijs Frans De Potter en Jan Broeckaert toegewezen aan een vorser met een archeologische academische vooropleiding. Alle onderzoek dat ik deed, aanstuurde en/of coördineerde, vertrekt bij wat de materiële bronnen over het verleden van een bepaalde plek en van de mensen op die plek vertellen. Voornamelijk bij de archeologen-mediëvisten eindigt de wetenschappelijke opdracht niet bij de beschrijving van de vondsten en sporen die via archeologisch onderzoek aan het licht komen. We vergelijken ze met gegevens die uit andere bronnen, geschreven data en beeldmateriaal, worden aangereikt en schrijven een nieuw syntheseverhaal. Zo bouwen we mee aan veelal gewijzigde inzichten over de onderzoekplek, haar ontwikkeling doorheen de tijd en haar situering binnen de ruimere context van stad of platteland in wat je als het Noordwest-Europese Lebensraum kan definiëren. 
Een derde vernieuwing zit voor mij vervat in de bekroning van iemand die vooral in teamverband onderzoek verrichtte. En die samenwerkingsverbanden waren en zijn zeer breed vertakt. Voor het onderzoek van de materiële bronnen ben je namelijk aangewezen op eigenaars, bouwheren, aannemers en archeologische teams met zowel grondwerkers en technici, als archeologen. Voor de verwerking reken je voorts op samenwerking met collega's (historici, archeologen, natuurwetenschappers) en de (financiële) mogelijkheden die vooral overheden ter beschikking stellen. Met andere woorden, als ik vandaag in de bloemetjes word gezet, dan worden allen erkend die binnen Stadsarcheologie Gent of in andere samenwerkingsverbanden aan onderzoekaspecten hebben meegewerkt. En langs deze weg wil ik ook die velen van harte danken om zo mee te bouwen aan nieuwe inzichten over Gent en haar onmiddellijke randgebied.

Met deze vernieuwende aspecten wordt mijn naam thans geassocieerd met die van Frans De Potter en Jan Broeckaert. Beide auteurs zijn immers incontournable voor wie iets wil weten over bijvoorbeeld de Gentse deelgemeenten. Net zoals zoveel andere plaatsen in Oost-Vlaanderen is dit een eerste stap om dan verder uit te zoeken welke onderzoekweg men wil opgaan. Voor wie in het kerngebied van Gent werkt is, er uiteraard het onoverkomelijke achtdelige Gent van den oudsten tyd tot heden (1883-1901) en zijn er nog een hele reeks andere publicaties zoals de Petit Cartulaire de Gand (1885) of de Second Cartulaire de Gand (1886) en notities in de Nota's Straten van het Gentse Stadsarchief. In de lijn van de kritische stem die tijdgenoten zoals Julius Vuylsteke (1836-1903) $)^{1}$ en Victor Fris (1877-1925) $)^{2}$ lieten horen, vormden de werken van De Potter ook voor ons geen eindpunt en behoorden we tot de toch eerder uitzonderlijke vorsers rond stad en materieel patrimonium voor wie het herhalen van De Potter geen optie was ${ }^{3}$. Zo lag zijn werk, of liever waren de discrepanties in zijn basispublicatie, een aanzet voor twee belangrijke vernieuwingen in het Gentse onderzoek. Als eerste vermelden we het project rond de middeleeuwse stenen stadshuizen. Dit project omvat onder meer de Steneninventaris die door Stadsarcheologie Gent werd opgemaakt en ook nu nog regelmatig wordt aangevuld. Een eerste synthese van de bevindingen, die ik samen met Patrick Raveschot uitwerkte, werd in 1989 bekroond door de Koninklijke Academie voor

\footnotetext{
J. Vuylsteke, 'Een handvol misslagen uit het VIe deel van Gent door F. De Potter', in Nederlandsch Museum, Gent, 1893, pp. 139-186.

2 V. Fris, Bibliographie de l'histoire de Gand depuis les origines jusqu'à la fin du XVe siècle, Gand, 1907, zie vooral pp.90-95.

3 Zie ook: M.C. Laleman \& D. Lievois, 'De wetenschappelijke betekenis van Frans De Potters 'Gent. Van den oudsten tijd tot heden”, in S. Meersseman, Gent van den oudsten tijd tot heden. Registers op het werk van Frans De Potter, (Verhandelingen der Maatschappij voor Geschiedenis, 27), Gent, 2002, pp. 15-24.
} 
Wetenschappen, Letteren en Schone Kunsten van België́4. Een andere stimulans die van De Potter's discrepanties uitging, resulteerde in het zogenoemde huizenonderzoek, een interdisciplinaire benadering van de perceelgeschiedenis, waarvoor we samen met archivaris Leen Charles, bouwhistoricus Guido Everaert en historicus Daniel Lievois twee handleidingen schreven ${ }^{5}$. De hoofdstructuur vindt quasi dagelijks toepassing bij een grote groep mensen die meer over hun huis willen en/of moeten weten, onder meer in het kader van verbouwingen.

Het doorgeven van kennis naar een zo ruim mogelijk publiek en via diverse kanalen heeft altijd deel uitgemaakt van mijn visie over hoe je het verleden in de wereld van vandaag kan verankeren en met een blik op de toekomst gestalte wil geven. Toch blijft de strikt wetenschappelijke benadering, vertolkt in geannoteerde, gepubliceerde bijdragen, het uitgangspunt, samen met een zo trouw mogelijke weergave van wat de historische realiteit zou kunnen zijn, zelfs al moet dit soms aan nieuwe inzichten worden aangepast. Deze visie, die heden ten dage soms als 'ouderwets' wordt bestempeld, zal ik blijven uitdragen. Ik geloof namelijk niet in de maatschappelijke meerwaarde van vluchtige, op succes gerichte en vaak duur betaalde evenementen met een fake historisch sausje. Gestimuleerd door de erkenning met de Prijs Frans De Potter en Jan Broeckaert hoop ik ook de komende jaren deze visie nog verder te kunnen uitdragen. Dank dat u dit mede mogelijk maakt.

4 M.C. Laleman \& P. Raveschot, Inleiding tot de studie van de woonhuizen in Gent. Periode 1100-1300. De kelders, (Verhandelingen Koninklijke Academie voor Wetenschappen, Letteren en Schone Kunsten van België), Brussel, 1991.

5 L. Charles, G. Everaert, M.C. Laleman \& D. Lievois, Huizenonderzoek in Gent. Het Elisabethhuis, Gent, 1997; L. Charles, G. Everaert, M.C. Laleman \& D. Lievois, Erf, huis en mens. Huizenonderzoek in Gent, Gent, 2001. 